\title{
Meliponini neotropicais: o gênero Ptilotrigona Moure (Hymenoptera, Apidae, Apinae)
}

\author{
João M. F. Camargo ${ }^{1,2} \&$ Silvia R. M. Pedro ${ }^{1}$
}

\begin{abstract}
${ }^{1}$ Departamento de Biologia, Faculdade de Filosofia, Ciências e Letras de Ribeirão Preto, Universidade de São Paulo. Av. Bandeirantes 3900, 14040-901 Ribeirão Preto-SP, Brasil. Endereço eletrônico: jmfdcama@usp.br - silviarmp@ffclrp.usp.br ${ }^{2}$ Pesquisador do CNPq.
\end{abstract}

\begin{abstract}
Neotropical Meliponini: the genus Ptilotrigona Moure, (Hymenoptera, Apidae, Apinae). The Neotropical stingless bees genus Ptilotrigona Moure, 1951 is revised. Three species are recognized: Ptilotrigona occidentalis (Schulz, 1904), endemic to NW South America - from NW Ecuador to southern Darién -, and with one isolated population in Osa Peninsula - Costa Rica; P. pereneae (Schwarz, 1943), endemic to the western Amazon; and P. lurida (Smith, 1854), largely distributed in the Amazon region. Ptilotrigona lurida and P. pereneae are the only known stingless bees that store pollen in association with yeasts (Candida sp.) and produce little or no honey. Nests are described and illustrated. Holotypes of Trigona suffragata Cockerell, 1922 (syn. of P. occidentalis) and Trigona manni Cockerell, 1912, specimens of Trigona heideri Friese, 1900 (syns. of P. lurida) identified by Friese, and one paratype of Trigona (Tetragona) heideri pereneae Schwarz, 1943 were studied. New synonym: Ptilotrigona lurida (Smith, 1854) = Trigona mocsaryi lutea Friese, 1903 syn. nov. In the cladistic analysis, species of Camargoia Moure, 1989, and Tetragona Lepeletier \& Serville, 1828, were used as outgroups; the hypothesis presented is the following: ((( Ptilotrigona lurida, P. pereneae $)$ P. occidentalis)((Camargoia nordestina, C. pilicornis) C. camargoi $))$ Tetragona goettei). An identification key for the species and other bionomic aspects are also presented.
\end{abstract}

Keywords. Candida; phylogeny; Ptilotrigona; stingless bees; taxonomy.

Resumo. O gênero neotropical de abelhas sem ferrão, Ptilotrigona Moure, 1951, é revisado. Três espécies são reconhecidas: Ptilotrigona occidentalis (Schulz, 1904), endêmica do NW da América do Sul - do NW do Equador até o sul de Darién , e com uma população isolada na Península de Osa - Costa Rica; P. pereneae (Schwarz, 1943), endêmica do oeste da Amazônia, e P. lurida (Smith, 1854), amplamente distribuída na Amazônia. Ptilotrigona lurida e P. pereneae são as únicas abelhas sem ferrão que estocam pólen em associação com leveduras (Candida $\mathbf{s p}$.) e produzem pouco ou nenhum mel. Ninhos são descritos e ilustrados. Holótipos de Trigona suffragata Cockerell, 1922 (sin. de P. occidentalis) e Trigona manni Cockerell, 1912, e exemplares de Trigona heideri Friese, 1900 (sins. de P. lurida), identificados por Friese, e um parátipo de Trigona (Tetragona) heideri pereneae Schwarz, 1943, são estudados. Novo sinônimo: Ptilotrigona lurida $($ Smith, 1854) = Trigona mocsaryi lutea Friese, 1903 syn. nov. Na análise cladística, espécies de Camargoia Moure, 1989, e Tetragona Lepeletier \& Serville, 1828, foram incluídas como grupos externos; a hipótese apresentada é a seguinte: ((((Ptilotrigona lurida, P. pereneae) P. occidentalis $)(($ Camargoia nordestina, C. pilicornis $)$ C. camargoi $))$ Tetragona goettei). Uma chave de identificação para as espécies e outros aspectos bionômicos também são apresentados.

Palavras-Chave. Abelhas sem ferrão; Candida; filogenia; Ptilotrigona; taxonomia.

Ptilotrigona Moure, 1951, é um gênero de abelhas sociais, sem ferrão, endêmico das matas tropicais do norte-noroeste da América do Sul; no lado oeste dos Andes ocorre do noroeste do Equador até Darién no Panamá e na península de Osa em Costa Rica. Três espécies são reconhecidas até agora: Ptilotrigona lurida (Smith, 1854), P. pereneae (Schwarz, 1943) e $P$. occidentalis (Schulz, 1904). São abelhas de porte médio (8-9 mm de comprimento), de corpo amarelado ou amareladoenegrecido, e nidificam em ocos de árvores. $\mathrm{Na}$ região do Chocó, Colômbia, são conhecidas pelo nome de "abejas de brea", dado que armazenam grandes quantidades de resinas, as quais são extraídas e utilizadas pelos nativos da região. Em algumas regiões da Amazônia brasileira, recebem o nome de "abelhas piranhas", devido ao fato de defenderem os ninhos com grande "agressividade" e por morderem, insistentemente, com suas potentes mandíbulas. Não há notícias de que sejam exploradas economicamente na Amazônia. Uma das peculiaridades de $P$. lurida e $P$. pereneae é que armazenam pólen, em grandes quantidades, em associação com leveduras - Candida sp. (CAMARgo et al. 1992).

No presente trabalho são apresentadas a revisão taxonômica do gênero, hipótese de relações filogenéticas, distribuição geográfica das espécies e descrições detalhadas dos hábitos de nidificação e modos de vida.

\section{MATERIAL E MÉTODOS}

Foram examinados cerca de 5.500 exemplares secos, montados em alfinetes, além de amostras preservadas em álcool, obtidas de 38 ninhos. A maior parte dos espécimens secos, todo o material em fixador e peças dos ninhos, estão depositados na Coleção do Departamento de Biologia da Faculdade de Filosofia, Ciências e Letras de Ribeirão Preto, Universidade de São Paulo (RPSP, coleção Camargo). Outras instituições que forneceram material e respectivos curadores estão listados abaixo; as abreviações são as recomendadas 
por ARNETT et al. (1993): AMNH - American Museum of Natural History, New York, EUA (J. G. Rozen Jr. / M. G. Rightmyer); DZUP - Departamento de Zoologia, Universidade Federal do Paraná (G. A. R. Melo); UNALM - Museo de Entomologia, Universidad Nacional Agraria La Molina, Lima, Peru (C. Vergara / Claus Rasmussen); EMEC - Essig Museum of Entomology, University of California, Berkeley, EUA (R. Zuparko); LACM - Los Angeles County Museum of Natural History, Los Angeles, EUA (R. R. Snelling); MSUC - Michigan State University Collection, East Lansing, EUA (F. W. Stehr / G. L. Parsons); MUSM - Coleccion del Departamento de Entomologia, Museo de Historia Natural, Universidad Nacional Mayor de San Marcos, Lima, Peru (G. Lamas / C. Rasmussen); SEMC - Snow Entomological Museum, Lawrence, EUA (R. Brooks, curador na ocasião); STRI - Smithsonian Tropical Research Institute, Panamá (D. W. Roubik); USNM - United States National Entomological Collection, U. S. National Museum of Natural History, Washington, EUA (R. J. McGinley / D. G. Furth).

Para a interpretação das espécies e composição das listas sinonímicas, foram examinados os holótipos de Trigona suffragata Cockerell, 1922 e Trigona manni Cockerell, 1912, e um parátipo de Trigona (Tetragona) heideri pereneae Schwarz, 1943. A interpretação de Ptilotrigona lurida (Smith, 1854), foi feita com base no trabalho de Moure (1963: 263-264) que estudou a Coleção Spinola e selecionou o exemplar tipo de Trigona testacea Spinola, 1853 (non Klug, 1807). De Trigona heideri Friese, 1900, foram examinados exemplares com etiquetas de "TYPUS" designados por Friese, em data posterior, mas que não pertencem à série-tipo original. Trigona heideri occidentalis Schulz, 1904, Trigona mocsaryi Friese, 1900 e Trigona mocsaryi lutea Friese, 1903, foram interpretadas com base nas descrições originais.

Nas listas sinonímicas, quando o nome do(s) autor(es) aparece precedido de interrogação (?), significa que há dúvidas quanto à identidade da espécie.

A terminologia empregada está de acordo com PEDRO \& CAmargo (2003). Tergos e esternos abdominais são indicados com TII-TVIII e EII-EVIII, considerando que o $1^{\circ}$ tergo abdominal (propódeo) está incorporado ao tórax. O termo metaposnoto define a área usualmente denominada, na literatura sobre Meliponini, como área basal do propódeo ou disco basal do propódeo; compreende a área aproximadamente triangular entre as margens do metanoto até a fóvea propodeal ( $3^{\circ}$ fragma) e, nos lados, até próximo aos espiráculos propodeais. Em Ptilotrigona o metaposnoto não tem limites discretos, distingue-se apenas pelo integumento pontilhadopilo-plumoso. As pernas são indicadas com numerais romanos - I, II, III; as asas são referidas apenas como anteriores e posteriores.

A nomenclatura utilizada nas descrições dos ninhos segue Camargo (1970) e Wille \& Michener (1973).

Os desenhos anatômicos foram feitos com auxílio de câmara clara acoplada ao estereomicroscópio LEICA MZ APO.

Nos itens "Material examinado", foram transcritos os dados das etiquetas de procedência e de todas as demais etiquetas adicionadas pelos autores precedentes, apenas os meses foram indicados em algarismos romanos e os anos com quatro algarismos. Países e subdivisões (estado, departamento, províncias, etc.) foram listados de oeste para leste e de norte para sul, conforme ZANELla et al. (2000).

Para a análise cladística, a matriz de dados foi processada através do programa PAUP, versão 4.0b10 (SwOFFORD 2002) e MacClade, versão 3.05 (MADDison \& MAdDison 1992). Foram eleitos como grupos externos, com base nas hipóteses de relações filogenéticas apresentadas por CAMARGo (1996) e CAmargo \& Pedro (2003b), todas as três espécies conhecidas de Camargoia Moure, 1989 - C. pilicornis (Ducke, 1916), C. camargoi Moure, 1989 e C. nordestina Camargo, 1996 - , e, de Tetragona Lepeletier \& Serville, 1828, apenas uma espécie, $T$. goettei (Friese, 1900).

\section{Ptilotrigona Moure, 1951}

Trigona (Ptilotrigona) Moure, 1951: 47.

Espécie-tipo: Trigona heideri Friese, 1900 = Trigona lurida Smith, 1854 (por designação original).

Ptilotrigona; Nogueira-Neto, 1970: 32; Camargo \& Moure, 1988: 293 (não publicado desta forma, por inferência)

Trigona (Tetragona); Wille, 1979: 264; Michener, 1990: 123; 2000: 803 .

Moure (1951) propôs o subgênero Ptilotrigona (do Grego, ptilon $=$ tufo de pêlos + Trigona, supondo-se que o autor se referia à pilosidade do metaposnoto) subordinado ao gênero Trigona Jurine, 1807, elegendo como espécie-tipo Trigona heideri Friese, 1900 (= Trigona lurida Smith, 1854). Nos anos subseqüentes, principalmente na literatura não estritamente taxonômica, os nomes das espécies de Ptilotrigona aparecem em diferentes combinações genéricas e subgenéricas ( $c f$. listas sinonímicas referentes a cada uma das espécies). As únicas abordagens formais, de caráter taxonômico, foram feitas por Wille (1979), que trata T. (Ptilotrigona) como sinônimo de $T$. (Tetragona), e Michener (1990; 2000), que reitera essa classificação. Neste trabalho, optou-se pelo tratamento de Ptilotrigona como gênero, como já sugerido por NogueIRAneto (1970) e CAmargo \& Moure (1988).

A diagnose abaixo, para operárias, está em conformidade com os itens considerados em trabalhos anteriores (CAMARGO \& Moure 1996; Pedro \& CAmargo 2003), apenas a ordem de apresentação foi um pouco alterada e os caracteres distintivos são indicados em destaque.

Diagnose. Operárias. a- Comprimento do corpo entre 8 e 9 mm. b- Integumento liso, polido, apenas com pontuação pilígera. c- Cor do corpo variando desde predominantemente amarelada-ferrugínea até enegrecida; membrana das asas levemente tingida de amarelo-ferrugíneo; cabeça preta, exceto pelos desenhos amarelos adiante descritos. d- Desenhos amarelos, todo o clípeo (às vezes com pequenas estrias enegrecidas a cada lado), área supra-clipeal, entre os alvéolos antenais, e áreas paroculares inferiores até a altura do meio 
do olho, preenchendo todo o espaço entre as órbitas e a sutura epistomal e, em cima, terminando em um arco que vai da altura do meio do olho até a parte superior dos alvéolos antenais; a sutura epistomal fortemente demarcada com uma linha negra (Figs. 28-30); amarelas, a face anterior do escapo das antenas, pequena estria pronotal, uma estria a cada lado do mesoscuto e as axilas; o escutelo, às vezes, com pigmento amarelo subcuticular. e- Cerdas eretas esparsas, amareladas, em todo o corpo; na face e mesoscuto intercalada com fina micropilosidade plumosa, decumbente; nas genas a micropilosidade plumosa ainda mais evidente, com reflexos prateados e recobrindo todo o integumento; metaposnoto recoberto, inteiramente, por pilosidade plumosa, fina, densa, ereta e semi-ereta e de cor amarelada. f-Cabeça ca. de 2,603,00 mm de largura, levemente mais larga que o tórax; a interorbital máxima aproximadamente igual ao comprimento do olho; as órbitas internas dos olhos levemente sinuosas e convergentes embaixo; tangente superior dos alvéolos antenais levemente acima do meio da face (considerando a face do vértice ao ápice do clípeo); vértice, atrás dos ocelos, arredondado; área malar igual ou levemente mais longa que metade do diâmetro do $1^{\circ}$ flagelômero; rebordo pré-occipital apenas levemente arredondado; genas, vistas de perfil, mais largas que a largura do olho. g-Clípeo ca. de 1,75 vezes mais largo que longo (Figs. 28-30), levemente protuberante, abaulado; a sutura epistomal, entre as suturas subantenais, nitidamente arqueada para baixo. h- Labro normal, levemente abaulado e a margem distal traçando um semicírculo. iMandíbula com dois dentes relativamente grandes, pontiagudos, ocupando a metade interna do bordo apical (Fig. 26). j- Escapo ca. de 1,20-1,28 vezes mais longo que a distância entre o alvéolo antenal e o ocelo lateral; o segundo flagelômero ca. de 1,30 vezes mais longo que largo, praticamente subigual ao primeiro e ao terceiro. k- Margem anterior do pronoto apenas com leve reentrância mediana (Fig. 25). l- Escutelo curto, duas vezes mais largo que longo, arredondado; a margem posterior em semicírculo, apenas recobrindo o metanoto em vista superior; sem fóvea basal. m- Asas anteriores um pouco mais longas que o comprimento do corpo, ultrapassando o ápice do abdômen em ca. de 1/4 de seu comprimento, e ca. de 2,60 vezes mais longa que a tíbia III; pterostigma ca. de 1,35 vezes a largura do $2^{\circ}$ flagelômero e $1 / 4$ de seu próprio comprimento; célula marginal ca. de 4,20 vezes mais longa que larga, lanceolada e levemente aberta no ápice; bifurcação entre M e $\mathrm{Cu}$, anterior à cu-a; ângulo submarginal, entre Rs e Rs+M, muito aberto, ca. de $140^{\circ}$; ângulo entre $\mathrm{Me} \mathrm{Rs}+\mathrm{M}$, praticamente reto; $2^{\mathrm{a}}$ abscissa da $\mathrm{M}$ (entre a $2^{\mathrm{a}}$ abscissa de Rs e $1^{\mathrm{a}} \mathrm{m}+\mathrm{cu}$ ) um pouco recurvada; $1^{\text {a }}$ abscissa de $\mathrm{M}$ ca. de 1,10 vezes mais longa que a $1^{\mathrm{a}}$ abscissa da $\mathrm{Cu}$; células submarginais nulas, apenas com fraca indicação das veias limitantes, confluentes em cima ( $2^{\mathrm{a}}$ abscissa de $\mathrm{Rs}$ e $\left.1^{\mathrm{a}} \mathrm{r}+\mathrm{m}\right)$; asas posteriores com venação normal; 6-7 hâmulos; lóbulo jugal ca. de metade do comprimento do anal. n- Tíbia III subclaviforme e mais fortemente expandida em direção ao ápice, a partir do meio; a margem anterior levemente recurva, e a posterior sinuosa no meio; o canto póstero-distal largamente arredondado (Fig. 27); corbícula fracamente côncava, ocupando toda a área expandida distal, que corresponde a pouco menos que metade do comprimento da tíbia; cerdas corbiculares da margem posterior, simples, intercaladas com cerdas ramificadas principalmente no canto distal (Fig. 27); face interna com área elevada quirotriquiada muito alta e mais estreita que a margem posterior, profundamente rebaixada; pente e penicilo normais. o- Basitarso III estreito, ca. de metade da largura da tíbia, ou de seu próprio comprimento, subretangular, de lados suavemente divergentes para o ápice; o canto póstero-distal em ângulo reto ou levemente agudo (Fig. 27); face interna sem área basal sedosa, revestimento cerdoso irregular. p- Metaposnoto relativamente protuberante; o disco basal em declive de ca. de $20^{\circ}$ e o terço posterior vertical. q- Abdômen estreito e alongado, do tipo tetragonóide. r- Ninhos em ocos de árvores; as espécies conhecidas são muito agressivas, mordem e perseguem com insistência.

Em relação aos gêneros mais proximamente relacionados Camargoia e Tetragona, pode-se distinguir facilmente Ptilotrigona pelos caracteres acima marcados em destaque, como dentes da mandíbula muito grandes, forma da mancha amarela parocular terminando em arco acima dos alvéolos antenais, pelo metaposnoto inteiramente revestido por cerdas plumosas e pelas genas, vistas de perfil, mais largas que o olho composto. Os dois primeiros caracteres são autapomorfias do gênero; a pilosidade no metaposnoto é compartilhada com as espécies de Camargoia, porém, nestas há uma larga faixa glabra mediana dividindo longitudinalmente a área discal pilosa. Genas largas é um caráter homoplástico, aparecendo também, por exemplo, em algumas espécies de Trigona (s. str.).

A monofilia de Ptilotrigona é presumida, não só pelos caracteres de operárias acima relacionados, mas também por alguns caracteres (sinapomorfias) dos machos e atributos comportamentais como: EVI aproximadamente sub-retangular na porção entre os apódemas (Figs. 9, 13), ápice da projeção mediana do EVII terminando, ventralmente, em um espículo (Fig. 11) e forma da espata da genitália, pequena e muito aberta apicalmente (Figs. 17-19). O caráter 4.1 (Tabela I), ganchos das valvas muito longos (Figs. 17-19), é compartilhado com pelo menos uma espécie de Tetragona, que não foi incluída na análise, conforme discutido adiante. Entre os caracteres comportamentais, o mais significativo é a associação de leveduras junto ao pólen estocado (compartilhado por $P$. lurida e $P$. pereneae; de $P$. occidentalis não há dados disponíveis).

\section{Relações filogenéticas.}

Hipóteses de relações filogenéticas para os gêneros neotropicais do ramo Trigona - Tetragona foram apresentadas por CAmargo (1996) e CAmargo \& Pedro (2003b). Em ambas as hipóteses, Ptilotrigona e Camargoia são considerados como grupos irmãos, dentro de um conjunto monofilético maior, que inclui Tetragona. Apenas duas sinapomorfias são indicadas nesses trabalhos como justificativa para a hipótese de compartilhamento de um ancestral comum para esses três 
Tabela I. Matriz de caracteres para as espécies de Ptilotrigona e gêneros relacionados.

\begin{tabular}{lllllllllllllllllllll}
\hline & 01 & 02 & 03 & 04 & 05 & 06 & 07 & 08 & 09 & 10 & 11 & 12 & 13 & 14 & 15 & 16 & 17 & 18 & 19 & 20 \\
\hline Tetragona goettei & 1 & 0 & 0 & 0 & 0 & 0 & 0 & 0 & 0 & 0 & 0 & 0 & 0 & 0 & 0 & 0 & 0 & 0 & 0 & 0 \\
Camargoia nordestina & 0 & 1 & 0 & 0 & 1 & 1 & 0 & 3 & 1 & 0 & 1 & 0 & 1 & 1 & 2 & 0 & 1 & 1 & 0 & 0 \\
Camargoia pilicornis & $?$ & $?$ & $?$ & $?$ & $?$ & $?$ & $?$ & $?$ & 1 & 0 & 1 & 0 & 1 & 1 & 2 & 0 & 1 & $?$ & $?$ & $?$ \\
Camargoia camargoi & 0 & 1 & 0 & 0 & 1 & 1 & 0 & 3 & 1 & 0 & 1 & 0 & 0 & 1 & 1 & 2 & 0 & 1 & 0 & 0 \\
Ptilotrigona lurida & 2 & 1 & 1 & 1 & 1 & 2 & 1 & 1 & 0 & 1 & 1 & 1 & 0 & 2 & 0 & 1 & 0 & 0 & 1 & 1 \\
Ptilotrigona pereneae & 2 & 1 & 1 & 1 & 1 & 2 & 1 & 1 & 0 & 1 & 1 & 1 & 0 & 2 & 0 & 1 & 0 & 0 & 1 & 1 \\
Ptilotrigona occidentalis & 2 & 1 & 1 & 1 & 1 & 1 & 1 & 2 & 0 & 1 & 1 & 1 & 0 & 2 & 0 & 1 & 1 & 0 & $?$ & 1 \\
\hline
\end{tabular}

gêneros: pêlos plumosos na área discal do último tergo abdominal, e EVIII dos machos, longo, estreitado e com a antecosta em forma de Y. Outros caracteres utilizados, principalmente por CAMARGO (1996), como forma do EVII e forma dos gonocoxitos, não são compartilhados por todas as espécies de Tetragona - machos de várias espécies ainda não eram conhecidos naquela ocasião. Todavia, algumas outras sinapomorfias não espúrias, podem ser acrescentadas em corroboração a essa hipótese, como: manchas paroculares preenchendo o espaço entre as órbitas e a sutura epistomal e truncadas em cima (caráter 16.0.2, Tabela I), independentemente da extensão da mancha [exceto em Tetragona essequiboensis (Schwarz, 1940), que é toda preta], tíbia III expandida a partir do meio, aproximadamente, e o canto posterior largamente arredondado (caráter 13, Tabela I, Figs. 24,27 ), metaposnoto relativamente protuberante e a veia que limita a parte distal da célula Média da asa anterior (Rs+M e 2a abscissa de M), curvada para dentro, e praticamente perpendicular ao eixo da veia Radial.

Neste texto, portanto, optou-se pela hipótese de monofilia de Ptilotrigona, Camargoia e Tetragona. A matriz de dados (Tabela I) foi preparada de maneira a propiciar mais algum esclarecimento sobre as relações entre estes três gêneros, além das relações entre as espécies do grupo interno: Ptilotrigona.

Dentre os estudos preliminares para a codificação de caracteres e preparação da matriz, foram examinadas, além de todas as espécies conhecidas de Ptilotrigona e Camargoia, também várias espécies de Tetragona, para as quais havia machos disponíveis [T. goettei, T. clavipes (Fabricius, 1804), T. truncata Moure, 1971, T. dorsalis (Smith, 1854) e outras duas espécies não descritas do grupo dorsalis]. Isso foi feito considerando que em trabalhos anteriores não há nenhuma justificativa para a suposta monofilia de Tetragona. Encontrouse, de fato, uma considerável diversidade na forma da genitália e dos esternos pré-genitais, mas pelo menos uma apomorfia é compartilhada por todas as espécies de Tetragona examinadas: a margem distal do EVI dos machos com uma larga reentrância em V ou U invertidos. Diante desses problemas, e não sendo o escopo deste trabalho estudar as relações internas de Tetragona, deliberou-se incluir apenas T. goettei na matriz de dados (Tabela I).
São os seguintes os caracteres selecionados (1-8 machos, 9-17 operárias, 18-20 biologia):

1. Forma da margem distal do EVI: 0- em arco projetado, com ou sem pequena sinuosidade mediana (Fig. 5); 1- em arco projetado, com larga reentrância mediana aproximadamente em forma de $\mathrm{V}$ ou $\mathrm{U}$ invertidos (Fig. 1); 2- reta ou em arco levemente recurvo (Figs. 9, 13).

2. Forma da projeção mediana do EVII em vista de perfil: 0fortemente recurvo ventralmente (Fig. 3); 1- suavemente recurvo (Figs. 7, 11).

3. Ápice da projeção mediana do EVII com pequena protuberância ventral terminando em um espículo: 0 - ausente (Figs. 3, 7); 1- presente (Fig. 11).

4. Genitália, comprimento do gancho da valva: 0 - curto, até ca. de 2 vezes o comprimento do bulbo basal; 1- longo, ca. de 3 a 4 vezes o comprimento do bulbo basal (Figs. 17-19).

5. Gonocoxitos, forma, em vista ventral: 0- curto e largo (CAMARGo 1996: 88, fig. 38); 1- longo e estreitado (Figs. 17-19).

6. Gonocoxitos, forma da margem apical: 0- arredondada (CAMARGO 1996: 88, fig. 38); 1- subtruncada (ibidem: 87, figs. 31, 34; Fig. 19); 2- truncada-reta (Figs. 17-18).

7. Gonóstilos, forma: 0 - sinuoso, um pouco alargado no meio; 1 - reto, de lados paralelos.

8. Gonóstilos, forma do terço apical (aproximadamente): 0 estreitado para o ápice, extremidade arredondada (CAMARGO 1996: 88, fig. 38); 1- gradualmente alargado-clavado para o ápice, extremidade arredondada (Figs. 17, 18); 2- um pouco alargado próximo ao ápice, extremidade estreitada em forma de cinzel (Fig. 19); 3- bastante alargado-achatado, extremidade arredondada (CAMARGo 1996: 87, figs. 30, 33).

9. Pronoto, forma da margem anterior em vista dorsal: 0reta ou com leve reentrância mediana (Figs. 20, 25); 1- com larga reentrância mediana, aproximadamente em semicírculo (Fig. 22).

10. Dentes da mandíbula: 0- dois dentes pontiagudos no terço apical interno (Figs. 21, 23); 1- dois dentes muito grandes, pontiagudos, ocupando ca. de metade da margem apical interna (Fig. 26).

11. Comprimento da área malar: 0 - curta, ca. de 1/3 do diâmetro do $1^{\circ}$ flagelômero; 1 - longa, ca. de metade do diâmetro do $1^{\circ}$ flagelômero, ou pouco mais. 




Figs. 1-16. Machos, esternos abdominais. 1-4. Tetragona goettei (Arimã, rio Purus, AM, Brasil, ninho 369c): 1, EVI; 2, EVII; 3, EVII, perfil do ápice da projeção mediana; 4, EVIII. 5-8. Camargoia camargoi (Manaus, AM, Brasil): 5, EVI; 6, EVII; 7, EVII, perfil do ápice da projeção mediana; 8, EVIII. 9-12. Ptilotrigona lurida (Camanaus, rio Negro, AM, Brasil, ninho 727c): 9, EVI; 10, EVII; 11, EVII, perfil do ápice da projeção mediana; 12, EVIII. 13-15. P. occidentalis (Costa Rica, Osa Península, 7 Km N Mogos): 13, EVI; 14, EVII; 15, EVIII. 16. P. pereneae (Equador, Sucumbios, Sacha Lodge), EVIII. Escala $=1,0 \mathrm{~mm}$. 
12. Gena, largura em relação à largura do olho composto em vista de perfil: 0 - mais estreita; 1 - mais larga.

13. Forma da tíbia III: 0 - clavada, a margem posterior com sinuosidade mediana (Fig. 27); 1- clavada, a margem posterior com sinuosidade suave no terço basal (Fig. 24). A forma da tíbia III, com leve sinuosidade na região mediana da margem posterior, e o canto póstero-distal largamente arredondado, sem formar ponta ou ângulo, é compartilhada pelas espécies de Tetragona, Ptilotrigona e Camargoia camargoi, principalmente combinada com a forma da corbícula, ocupando a metade distal e levemente côncava. Em Camargoia nordestina e $C$. pilicornis a sinuosidade na margem posterior é um pouco mais basal e a área corbicular mais alargada (Fig. 24).

14. Metaposnoto: 0- glabro; 1- piloso, com faixa média longitudinal glabra; 2- piloso por inteiro. Nas espécies de Ptilotrigona o metaposnoto é inteiramente recoberto por fina pilosidade plumosa, mas em um exemplar de $P$. lurida do leste do Maranhão há uma estreita faixa longitudinal glabra. Nas espécies de Camargoia a faixa glabra longitudinal dividindo o metaposnoto é bem mais larga e nítida.

15. Pilosidade plumosa na margem posterior da tíbia III: 0 concentradas no quarto distal, esparsa e irregular (Fig. 27); 1formando franja ocupando a metade distal; 2 - formando franja bem regular e densa ocupando os 3/4 distais (Fig. 24).

16. Áreas paroculares, manchas amarelas: 0 - chegando até, no máximo, ao nível da tangente superior dos alvéolos antenais; 1- chegando até o meio do olho e terminando em arco que vai até a parte superior dos alvéolos antenais (Figs. 28-30); 2chegando até o terço superior do olho. As manchas amarelas paroculares, embora variem em extensão, principalmente entre as espécies de Tetragona, sempre preenchem o espaço entre as órbitas oculares e a sutura epistomal e, em cima, terminam truncadas ou oblíquas. Em T. goettei há um pequeno e estreito prolongamento da mancha, para cima, justaposto à órbita.

17. Cor do mesoscuto: 0- preto; 1- amarelo.

18. Substrato de nidificação: 0- em ocos de árvores; 1subterrâneo.

19. Pólen estocado em associação com leveduras: 0ausente; 1 - presente.

20. Comportamento de defesa: 0- não mordem, apenas sobrevoam o intruso; 1 - mordem com intensidade, perseguem o intruso. Além de Ptilotrigona, no ramo Trigona-Tetragona, apenas espécies do gênero Trigona (s.str.), mas não todas, são muito agressivas, e as espécies de Oxytrigona Cockerell, 1917, que também são muito agressivas, mas não mordem, apenas depositam substâncias cáusticas produzidas pelas glândulas mandibulares, sobre o intruso.

Para a análise cladística, a matriz de caracteres foi processada através do programa PAUP, busca "exaustiva", com todos os caracteres não ordenados e com pesos iguais. Foi obtida apenas uma árvore de comprimento mínimo (comprimento 28, $\mathrm{CI}=0,9643, \mathrm{HI}=0,0357, \mathrm{RI}=0,9630, \mathrm{RC}=$ 0,9286; Fig. 48).

A hipótese de relações de grupos irmãos entre Ptilotrigona e Camargoia, proposta por CAmargo (1996) e CAmargo \& Pedro (2003b), recebe alguma corroboração na análise aqui apresentada. Além da pilosidade plumosa no metaposnoto (caráter 14.1 - este estado tem surgimento independente apenas em Cephalotrigona Schwarz, 1940; CAMARGO \& PEDRo 2003b), as espécies desses gêneros compartilham, também, a forma dos gonocoxitos, longos e estreitos e com a margem distal subtruncada (caracteres 5.1 e 6.1), que é exclusiva desse clado. Os estados dos caracteres forma da margem distal do EVI e da projeção mediana do EVII, e comprimento da área malar (caracteres 1.0.2., 2.1 e 11.1) não podem ser hipotetizados com segurança no ramo ancestral, visto que variam muito nos grupos externos considerados em CAMARGO \& PedRo (2003b), bem como nos demais Meliponini.

É óbvio que, considerando Tetragona como um grupo monofilético, como discutido anteriormente, esse era o resultado esperado. Todavia, um estudo detalhado de machos de todas as espécies de Tetragona, quando disponíveis, pode, eventualmente, revelar uma outra história.

Deve-se destacar que, embora alguns caracteres morfológicos indiquem relações entre Ptilotrigona e Camargoia, o mesmo não ocorre com relação aos hábitos de nidificação e comportamento, como já discutido por CAMARGO (1996). As espécies de Camargoia constróem ninhos subterrâneos, muito modificados em termos de arquitetura, enquanto as espécies de Ptilotrigona constróem ninhos em ocos de árvores, tendo como principal peculiaridade, a associação de leveduras ao pólen estocado.

Com relação às espécies de Ptilotrigona, não foram encontrados caracteres suficientemente informativos que permitissem propor uma hipótese bem corroborada de relações filogenéticas. A hipótese de relações de espécies irmãs entre P. lurida e P. pereneae (Fig. 48), é justificada por apenas um estado de caráter derivado, margem distal do gonocoxito truncada-reta (caráter 6.2). O outro caráter, que corrobora essa topologia, forma do terço apical dos gonóstilos (8.1), é ambíguo, ou seja, o estado na espécie ancestral não é conhecido, tanto pode ser o estado 1 (clavado), como o estado 2 (em forma de cinzel), ou um outro estado qualquer. Os estados nas espécies dos grupos externos, ou mesmo em espécies de outros gêneros relacionados, conforme hipótese apresentada por CAMARGO \& PEDRO (2003b), são distintos e não informam a direção evolutiva. Quanto ao caráter 19 (pólen estocado em associação com leveduras), não há informações para $P$. occidentalis. Há, todavia, outros caracteres, sutis e de difícil codificação, e também não comparáveis com o grupo externo, que, combinados, podem constituir indícios de que a hipótese acima é a mais "acertada", como, por exemplo: em $P$. lurida e $P$. pereneae a pilosidade nos lados do EVI é mais forte, e com pêlos de maior calibre que aqueles da área discal (Fig. 9), e a margem externa dos gonocoxitos é reta ou levemente sinuosa (Figs. 17, 18); em P. occidentalis a pilosidade nos lados do EVI é pouco distinta daquela da área discal, e os lados dos gonocoxitos são abaulados (Figs. 13, 19). Por outro lado, um melhor conhecimento da biologia de $P$. pereneae e $P$. occidentalis, poderia, eventualmente, auxiliar no 



17
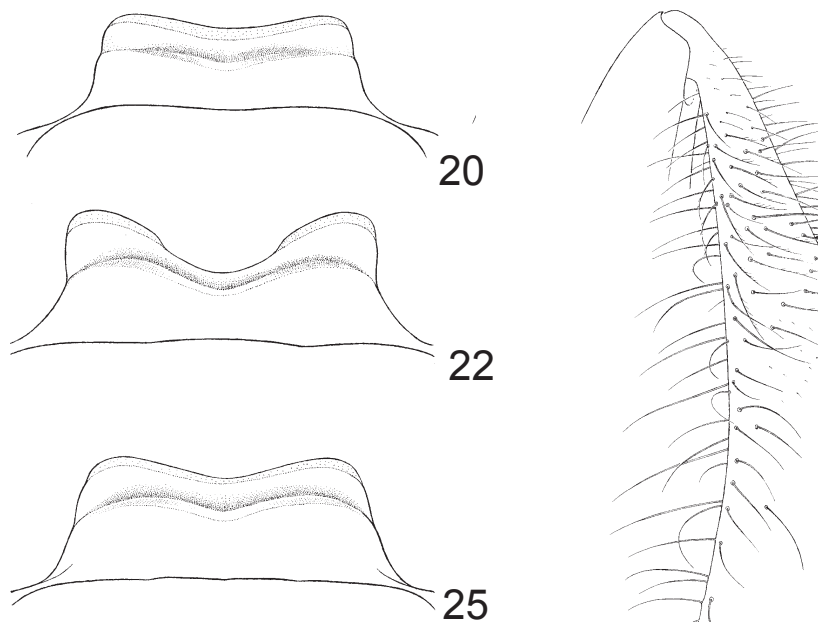

25

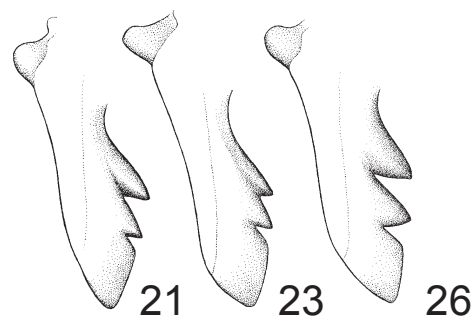

26



Figs. 17-27. 17-19, machos, genitália, vistas dorsal e ventral: 17, Ptilotrigona lurida (Caracaraí, RR, Brasil, ninho 272c); 18, P. pereneae (Equador, Sucumbios); 19, P. occidentalis (Costa Rica, Osa Península). 20-27, operárias, pronoto em vista superior, mandíbula e tíbia III: 20-21, Tetragona goettei; 22-24, Camargoia nordestina; 25-27, Ptilotrigona lurida. Escala $=1,0 \mathrm{~mm}$. 
esclarecimento da questão. A forma, ornamentação e textura do tubo de entrada, embora sejam caracteres importantes, variando em $P$. lurida e $P$. pereneae, não foram incluídas na matriz, visto que as informações para $P$. occidentalis não são precisas.

\section{Chave para as espécies de Ptilotrigona}

1. Mesoscuto amarelo ou ferrugíneo, às vezes um pouco enegrecido entre as linhas prescutais; nos machos, a pilosidade nos lados do EVI pouco distinta daquela da área discal (Fig. 13), e os lados dos gonocoxitos um pouco abaulados; ápice dos gonóstilos em forma de cinzel (Fig. 19). Matas da costa do Pacífico, do noroeste do Equador até Darién, ao sul do Panamá, e uma população isolada na península de Osa, Costa Rica (Fig. 46) P. occidentalis

Mesoscuto preto; nos machos, a pilosidade nos lados do EVI distinta, com pêlos de maior calibre que aqueles da área discal (Fig. 9), e os lados dos gonocoxitos retos ou levemente sinuosos; ápice dos gonóstilos dilatado-arredondados (Fig. 17, 18). Matas do lado oriental dos Andes, toda a Amazônia até o Piauí - Brasil, Guianas, Suriname e Venezuela .......... 2

2(1). Geralmente com o integumento enegrecido, principalmente os mesepisternos - apenas com uma faixa amarelada no meio -, e as pernas II e III. Matas da Amazônia ocidental - Peru, Equador, Colômbia e extremo oeste dos estados do Acre e Amazonas, Brasil (quando os exemplares de $P$. pereneae são mais amarelados, a distinção com relação a $P$. lurida pode ser muito difícil; ver item Discussão) (Fig. 46) P. pereneae

Integumento predominantemente amarelo; os mesepisternos, às vezes, levemente escurecidos na porção ventral; o terço distal da tíbia III e respectivo basitarso, pretos ou inteiramente amarelados. Toda a Amazônia, Bolívia, Peru, Equador, Colômbia, Brasil - até o leste do Piauí, e Venezuela, Guianas e Suriname (Fig. 46) P. lurida

\section{Ptilotrigona lurida (Smith, 1854)}

Trigona testacea Spinola, 1853: 93 (praeoc.).

Trigona lurida Smith, 1854: 410 (nom. nov. para T. testacea Spinola, 1853, non Klug, 1807); Engel \& Dingemans-Bakels, 1980: 345; ?Engel, 2001: 176.

Melipona lurida; Dalla Torre, 1896: 580.

Trigona heideri Friese, 1900: 389; Ducke, 1902a: 325; 1907: 89; Marianno, 1911: 101; Cockerell, 1920: 463; 1922: 8; 1930: 157; 1934: 62, fig. 5; Lutz, 1924: 217; Ihering, H. 1930 (1903): 712; Schwarz, 1932: 253; 1937: 286; Moure, 1944: 72; 1963: 263 (syn.); Ihering, R., 1968: 157; Wille, 1979: 265; Lenko \& Papavero, 1996: 262.

Trigona mocsaryi Friese, 1900: 390; Cockerell, 1920: 463; Moure, 1963: 263 (syn.).

Melipona (Trigona) mocsaryi; Ducke, 1902b: 290, 305.

Melipona (Trigona) heideri; Ducke, 1902b: 290, 304.
Trigona mocsaryi lutea Friese, 1903: 361. Syn. nov.

Trigona heideri mocsaryi; Schulz, 1904(1903): 822; Marianno, 1911: 102; Moure, 1944: 72.

Trigona heideri heideri; Schulz, 1904(1903): 821.

Trigona manni Cockerell, 1912: 48, 61; 1920: 463 (syn.); Lutz, 1924: 205, 207, 212, 218.

Melipona heideri; Ducke, 1916a: 13; 1916b: 67, 68 (partim, apenas os registros para as seguintes localidades: "Guyana hollandeza"; Estado do Pará: Oyapoc, Macapá, Mazagão, Marajó, Belém, Almerim, Óbidos, Rio Trombetas, Faro; Estado do Amazonas: Teffé, Santo Antonio do Iça; Estado do Maranhão: Alcântara e noroeste de Matto Grosso); 1925: 382 (partim); Lenko \& Papavero, 1996: 263.

Melipona heideri, aberr. mocsaryi; Ducke, 1916b: 67, 68, 69; 1925: 383.

Trigona (Tetragona) heideri heideri; Schwarz, 1938: 468, pl. 54, fig. D; 1940: 7 .

Trigona (Tetragona) heideri; Schwarz, 1948: 73, 75, 80, 83, 319; Michener, 2000: 803.

Trigona (Ptilotrigona) heideri; Moure, 1951: 47.

Trigona (Tetragona) heideri, var. mocsdryi [sic]; Reyne, 1962: 35.

Trigona (Ptilotrigona) lurida; Moure, 1963: 263; 1989: 77; Akahira \& Beig, 1967: 166, 169, 172, 173, 179, 180, 184; Kerr et al., 1967: 283; Camargo, 1970: 219; Cunha, 1973: 3, 14; 1991: 37; Posey, 1983: 71; Waddington et al., 1986: 97; Nates-Parra, 2001: 240 (partim).

Ptilotrigona heideri heideri; Nogueira-Neto, 1970: 32, 33.

Ptilotrigona lurida; Nogueira-Neto, 1970: 42; 1997: 370; Coloma, 1986: 103, 132, 133, 135; Moure, 1989: 73; Mota, 1992: 320, 321; Roubik, 1989: 416; Cruz-Landim \& Mota, 1990: 587; Ramalho et al., 1990: 471; Camargo et al., 1992: 391; Camargo, 1994: 50; Rêgo \& Brito, 1996: 239, 242, 246; Heard, 1999: 192, 193, 197; Oliveira, 2002: 629; Falcão et al., 2000: 9, 18; Silveira et al., 2002: 91, 246.

Trigona (Tetragona) lurida; Wille \& Michener, 1973: 14, 24, 48, 59, 71, 87, 94; ?Nates-Parra, 1983: 157; Michener, 1990: 88, 95, $105,119,120,124,125 ; 2000: 800,803$.

Trigona (Ptilotrigona) lurida lurida; Absy et al., 1984: 228, 231.

Trigona (Ptilotrigona) lurida mocsaryi; Absy et al., 1984: 228, 231.

Ptilotrigona lurida mocsaryi; Absy et al., 1984: 236; Camargo, 1988: 359; 1996: 84, 86, 88, 89; Camargo et al., 1992: 391, 392, 394; Oliveira et al., 1995: 17; Falcão et al., 2000: 19; Oliveira, 2001: $210,213$.

Ptilotrigona lurida lurida; Camargo, 1988: 359; Oliveira \& Morato, 1994: 291.

Ptilotrigona lurida pereneae; Camargo et al., 1992: 394 (err. ident.). Tetragona (Ptilotrigona) lurida; Michener \& Roubik, 1993: 258.

Ptilotrigona mocsaryi; Camargo, 1994: 50; Silveira et al., 2002: 91, 247.

Ptilotrigona cf. lurida; Mesquita \& Franciscon, 1995: 256; Lopes \& Machado, 1998: 82.

Diagnose. Operária. Largura da cabeça entre ca. de 2,37 e $2,85 \mathrm{~mm}$; comprimento da asa anterior, desde a base do esclerito Costal, entre 7,60 e 8,20 mm. Integumento predominantemente amarelo; cabeça preta, exceto pelas manchas amarelas na metade inferior da face (Fig. 28); mesoscuto preto, exceto pelas faixas laterais amarelas e parte superior das axilas; mesepisterno amarelo, às vezes um pouco escurecido embaixo; membranas das asas anteriores tingidas levemente de amarelo-ferrugíneo; microtríquias amareladas nos 3/4 basais da asa e escurecidas no quarto apical; nervuras amareladas; terço distal da tíbia III e respectivos basitarsos, pretos, variegados ou inteiramente amarelados. Macho. Cor do integumento, como nas operárias; cerdas nos lados do EVI fortes e de calibre maior que aqueles da área discal; ganchos da valva muito longos, ca. de 4,2 vezes 


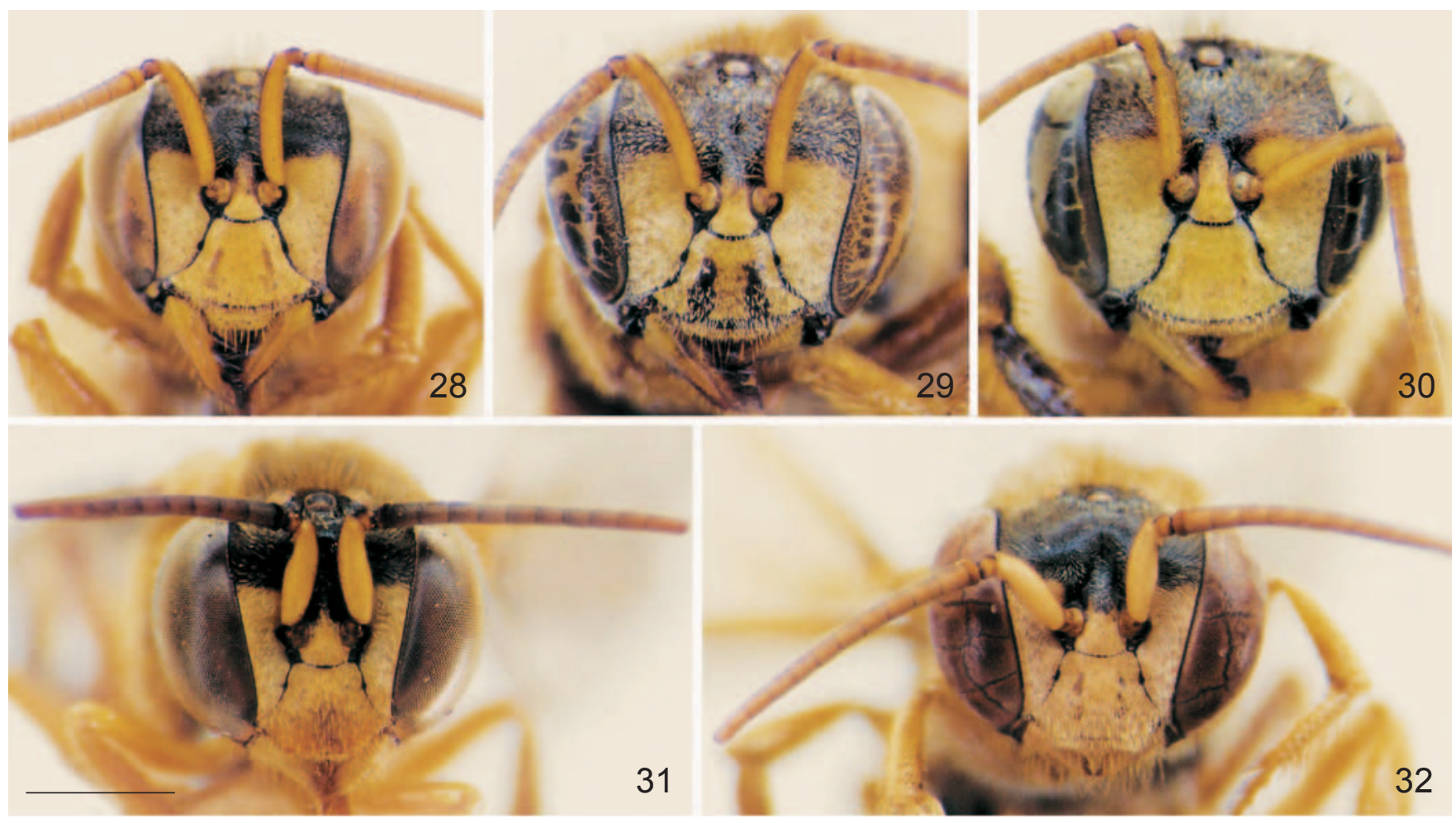

Figs. 28-32. Ptilotrigona: 28, P. lurida, operária (Belém, PA, Brasil, ninho 29c); 29, P. pereneae, operária (Sucumbios, Equador); 30, P. occidentalis, operária (Alto Tambo, Esmeraldas, Equador); 31, P. lurida, macho (Cujubim, RO, Brasil); 32, P. pereneae, macho (Sucumbios, Equador). Escala $=1,0 \mathrm{~mm}$.

o comprimento do bulbo basal (em vista de perfil); gonóstilos levemente dilatados e arredondados no ápice (Fig. 17).

\section{Macho. Figs. 9-12, 17, 31}

Material-tipo. O tipo (lectótipo), operária, do "Pará", Brasil, foi selecionado por Moure (1963: 263), dentre os três exemplares originalmente estudados e descritos por Spinola (1853: 93) com o nome de "Trigona testacea" (non Klug, 1807). De acordo com Moure, a série é composta, incluindo também Trigona williana Friese, 1900. Depositado na "Coleção Spinola", Instituto de Zoologia da Universidade de Turim. O tipo não foi examinado. Foram vistos o holótipo de Trigona manni e três exemplares de Trigona heideri, marcados por Friese como "TYPUS", mas que não pertencem à série-tipo original, conforme consta na lista abaixo.

Material examinado. COLÔMBIA. Meta: Puerto López, 26.VI.1985, D. Roubik (10 ops., STRI; 3 ops., RPSP); Restrepo, alt. $500 \mathrm{~m}, 1930$, J. Bequaert, acc. 35658, "Trigona (Tetragona) heideri heideri Friese, Det. Schwarz" (1 op., RPSP); ibidem, idem, 1936 [1930?], acc. 35658, "Trigona (Tetragona) heideri heideri Friese, Det. Schwarz" (2 ops., AMNH). Amazonas: Araracuara, Bosque Maduro, 7.IV.1988, Marcela Torres (1 op., 910009, RPSP); Letícia, 65 Km W, Amacayacu Nat. Park, 17-30.IX.1986, D. Roubik (10 ops., STRI; 3 ops., s/n, 1 op., 870335, RPSP). Departamento?: Monterredondo, XII.1959, 1420 mts., Förster, etiq. manuscrita de Moure: "Ptilotrigona 1. atromarginata M. 84" (1 op., DZUP) (foram encontradas, nos mapas, várias localidades e montanhas assinaladas como Monterredondo ou Monte Redondo, todas no lado ocidental dos Andes).VENEZUELA. Amazonas: Atures, Caño Ucata, Fibral nr. San Juan, $4^{\circ} 20^{\prime} \mathrm{N}, 67^{\circ} 45^{\prime} \mathrm{W}$, F. Guanchez, ex: Leopoldinia piassaba, male inflorescence ( 9 ops., SEMC; 2 ops., RPSP); Cerro de la Neblina, base camp, 120m, 5.II.1984, Rozen, Stupakoff (3 ops., AMNH); Mt. Duida, 4400 yr., 10.II.1929, G. H. H. Tate, no. 715, ac. 29500, "Trigona heideri Friese, Det. Schwarz" (1 op., AMNH); Puerto Ayacucho, $35 \mathrm{Km}$ SE, Tobogan de la Selva, 13.VII.1995, D. Roubik (8 ops., STRI, 2 ops., RPSP). GUIANA. Amatuk, "17.VIII.II. 39" [?, prov. 1911, no. 39; coletado por Lutz, de acordo com COCKERELL, 1920], anônimo, etiq. vermelha "METATYPE", "Am. Mus. Nat. Hist. Dept. Invert. Zool. no. 24510", etiq. manuscrita de Cockerell: "Trigona manni Ck11." (1 op., AMNH); Bartica District [sem localidade especificada], 6.V.1924, anônimo, "Trigona (Tetragona) heideri Friese, Det. Schwarz" (1 op., AMNH); Camaria, 31.VII.1924, J. F. W. Pearson, "Trigona (Tetragona) heideri, Det. Schwarz" (1 op., AMNH); Chenapowu, 31.VII.1911, anônimo [coletado por Crampton, de acordo com COCKERELL, 1920], etiq. vermelha "METATYPE", "Am. Mus. Nat. Hist. Dept. Invert. Zool. no. 24510" [não há etiq. de Cockerell] (1 op., AMNH); Georgetown, III.1955, M. Alvarenga, "T. (Ptilotrigona) lurida Sm. Det. J. S. Moure, 1982" (1 op., DZUP); ibidem, Soesdyke/CEIBA Biol. Ctr., 20.V-5.VII.1997, T. K. Distler, at flower: Astrocaryum vulgare (1 op., SEMC); Kaieteur, 3.VIII.1911, anônimo, "Ptilotrigona manni, det. M. S. Engel" (2 ops., AMNH); Kartabo, 29.VII.1920, W. M. Wheeler, acc. 35657, "Trigona heideri Friese, Det. Schwarz" (3 ops., RPSP); ibidem, idem, 29.VII.1929 \# 306, "Trigona heideri Friese, Det. Schwarz" (8 ops., AMNH); ibidem, idem, 17.VIII.1920, no. 529, "Trigona heideri Friese, Det. Schwarz", acc. 35657 (6 ops., AMNH); ibidem, idem, 12.IX.1920, "Trigona (Tetragona) heideri heideri (Friese), Det. Schwarz", acc. 35657 (16 ops., AMNH); ibidem, sem data, J. F. W. Pearson, "Trigona (Tetragona) heideri heideri Friese, Det. H. F. Schwarz" (2 ops., AMNH); ibidem, 10.IX.1920, anônimo, "Gift of New York Zool. Soc. Dept. Tropical Research, William Beebe, Dir.", "Trigona (Tetragona) heideri Friese, Det. H. F. Schwarz" (1 op., AMNH); ibidem, 26.III.1924, anônimo, 
"Gift of New York Zool. Soc. Dept. Tropical Research, William Beebe, Dir.", "Trigona (Tetragona) heideri Friese, Det. H. F. Schwarz" (1 op., AMNH); ibidem, 1.VI.1924, anônimo, "Gift of New York Zool. Soc. Dept. Tropical Research, William Beebe, Dir.", "Trigona (Tetragona) heideri Friese, Det. H. F. Schwarz" (1 op., AMNH); ibidem, 18.VIII.1920, anônimo, etiq. manuscrita: "Trigona (Tetragona) heideri Friese, Det. H. F. Schwarz" (1 op., USNM); Kuyuwini River, sem data, W. G. Hassler, Acc. 36159 (1 op., AMNH); Potaro Ldg., 18.VIII.1911, anônimo, ac. 38008, "Trigona manni Ckl1.", "Trigona heideri Fr." (1 op., AMNH); Upper Essequibo River, 23.XII.1937, anônimo, acc. 36159, "Trigona (Tetragona) heideri var. Friese, Det. by H. F. Schwarz" [etiq. de identificação em apenas um exemplar] (3 ops., AMNH); Waratuk, 16.II.1921, anônimo "Trigona (Tetragona) heideri Friese, Det. Schwarz" (2 ops., AMNH). GUIANA?: Mauru [? ilegível], sem data, apenas "April", anônimo, "Trigona (Tetragona) heideri var. heideri Friese, Det. H. F. Schwarz" (1 op., AMNH). SURINAME. Saramacca: West Suriname Road, $108 \mathrm{Km}$ WSW

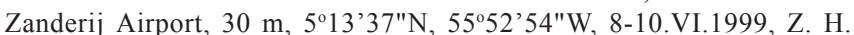
Falin, B. DeDijn, SUR1F99 054, ex: flight intercept trap, SM0188923, KUNHM-ENT (1 op., SEMC). Para?: Tibiti, savamerand ( $s i c=$ savannerand) 5.I.1949, D. G. Geuskes (1 op., DZUP); ibidem, idem, Dutch Guiana, 6.I.1949 (1 op., DZUP); ibidem, idem, savanna, 7.I.1949 (2 ops., DZUP); ibidem, idem, 8.I.1949 (1 op., DZUP). Departamento?: Suriname, sem localidade, 6.I.1949, D. G. Geuskes (3 ops., DZUP); Suriname Republiek, sem localidade, 22.II.1953, D. C. Geijske (1 op., DZUP). GUIANA FRANCESA. Saint-Laurent du Maroni: Saül, $3^{\circ} 37^{\prime} \mathrm{N}, 53^{\circ} 12^{\prime} \mathrm{W}, 1982$, Scott Mori, 65 (1 op., STRI); ibidem, 7 Km N, Les Eaux Claires, 3039'4"N, 5313'19"W, 220m, 4.VI.1977, J. Ashe, R. Brooks, FG1AB97 150, SM0103165, KUNHM-ENT (1 op., SEMC). Sinnamary: Sinnamary, 17 Km SW, 23.I.1977, D. Roubik (2 ops., RPSP); ibidem, idem, $30 \mathrm{Km} \mathrm{SW}$, 14.II.1977, no. 4 (1 op., SEMC); ibidem, idem, $10 \mathrm{Km} \mathrm{SE}$, palm plantation rd., 20.IV.1982, no. 61 (1 op., STRI); ibidem, idem, $15 \mathrm{Km} \mathrm{SE}$, palm plantation rd., 5.V.1982 (1 op., RPSP); ibidem, idem, 3-14 Km SW, 8.V.1989 (6 ops., STRI); ibidem, idem, $15 \mathrm{Km} \mathrm{SW}, 28 . V .1981$, no. 29 (1 op., STRI); ibidem, idem, 17 Km SW, 23.VI.1977, no. 2 (10 ops., SEMC). Kourou: Kourou, 5 Km SW, 20.II.1977, M. Winston, C. Michener (7 ops., SEMC; 3 ops., RPSP); ibidem, 19 Km SW, 22.II.1977, C. D. Michener (2 ops., SEMC); ibidem, idem, 19 Km SW, 5.III.1977 (1 op., SEMC); ibidem, idem, 26 Km SW, 5.III.1977, (7 ops., SEMC); ibidem, 16.VII.1977, C. D. Michener, T. Kukuk (1 op., SEMC); ibidem, 19 Km SW, 8.II.1977, D. Roubik, no. 87 (4 ops., SEMC); ibidem, idem, 17 Km SW, 20.II.1977, no. 91 (1 op., SEMC); ibidem, idem, 27 Km SW, 5.III.1977 (2 ops., SEMC); ibidem, idem, $12 \mathrm{Km} \mathrm{SW}$, 27.III.1977 (1 op., SEMC); ibidem, idem, 18 Km SSW, Degrad Saramaca, Log. Rd., 6.V.1982, no. 72 (42 ops., STRI; 5 ops., RPSP); ibidem, idem, 35 Km SW, 7.V.1994 (7 ops., STRI); ibidem, idem, $30 \mathrm{Km} \mathrm{W,} 11 \mathrm{Km} \mathrm{S}, 11 . \mathrm{V} .1989$, baits (18 ops., STRI; 4 ops., RPSP); ibidem, idem, $28 \mathrm{Km} \mathrm{W,} \mathrm{15.V.1981,} \mathrm{no.} 47$ (4 ops., STRI); ibidem, idem, $20 \mathrm{Km}$ WSW, 21.V.1981, no. 56 (3 ops., STRI); ibidem, idem, $30 \mathrm{Km} \mathrm{W,} \mathrm{24.V.1981,} \mathrm{no.} 46$ (1 op., STRI); ibidem, idem, $14 \mathrm{Km} \mathrm{SW}, 26 . V .1981$, no. 15 (1 op., STRI); ibidem, idem, $14 \mathrm{Km} \mathrm{SW}, 9 \mathrm{Km} \mathrm{S}$, sem data, baits (15 ops., STRI). Cayenne: Cayenne, 47 Km S, 23.II.1977, C. D. Michener, M. Winston, G. Otis (2 ops., SEMC); ibidem, idem, 65 Km S, $23 . I I .1977$ (1 op., SEMC); ibidem, idem, $81 \mathrm{Km} \mathrm{S}$, 23.II.1977 (2 ops., SEMC); ibidem, $68 \mathrm{Km}$ SE, 23.II.1977, D. Roubik, no. 6 (1 op., SEMC). Roura: Montagne de Kaw, nr. Km $41 \mathrm{SE}$ of Cayenne, $174 \mathrm{~m}, 4.58^{\circ} \mathrm{N}, 54.1^{\circ} \mathrm{W}, 9 . X I .1994$, J. Beier (1 macho, LACM); Roura, $8.4 \mathrm{Km} \mathrm{SSE}, 200 \mathrm{~m}, 4^{\circ} 40^{\prime} 41^{\prime \prime N}$, 52 ${ }^{\circ} 13^{\prime} 25^{\prime \prime W}, 24 . V .1977$, J. Ashe, R. Brooks, FG1AB97, ex: misc. collecting (1 op., SEMC); Route de Belizon PK, 10-19.X.1993, J. D. McCarty MV (6 ops., EMEC). EQUADOR. Sucumbios: Limoncocha, 10.VI.1984, Y. Carvajal (3 ops., RPSP); ibidem, 10.VI.1984, "nido en la base de um árbol", L. Coloma (2 ops., RPSP); ibidem, VI.1984, G. Onore, "Mishki putan" (4 ops., RPSP); ibidem, Oriente, 00²4'S, 76³6'W, 29.VI.1970, Carl W. Rettenmeyer (2 ops., SEMC); ibidem, Oriente, $00^{\circ} 24^{\prime}$ 'S, $76^{\circ} 36^{\prime}$ 'W, 6.VII.1970, M.G. Naumann, \# 71 (12 ops., SEMC, 3 ops., RPSP); ibidem, Napo-Pastaza Prov., 21.VI.1965, C. R. Patrick ( 2 ops., MSUC); Sacha Lodge, $76.5^{\circ} \mathrm{W}$, $0.5^{\circ} \mathrm{S}, 270 \mathrm{~m}, 1-31 . X I I .1994$, Hibbs, ex: malaise (2 ops., SEMC; 1 op., 000032, RPSP). Napo: Coca, III.1985, G. Onore (1 macho, RPSP);
Taracoa, V.1984, D. Bastidas, MECN (1 op., RPSP); Yasuni Nat. Park, Est. La Católica, 14-26.IV.1998, D. Roubik, no. 27 (2 ops., STRI); ibidem, idem, 13-27.IV.1998, nos. 19 e 42 (3 ops., STRI; 1 op., RPSP); ibidem, idem, 7-15.XI.1998, no. 54 (1 op., STRI). SantiagoMorona: Patuca, VII.1992, Roubik (1 op., STRI). PERU. Loreto: Iquitos, 21.VII.1964, G. H. Dodson (2 ops., DZUP). San Martín: Tarapoto, outside town on road to Yurimaguas, IV-VI.2001, Kanstrup (1 op., MUSM); Tarapoto-Yurimaguas [road], $\mathrm{Km} 20$, "BIODIVERSIDAD", [South] $0634 /$ [West] 7620, 950 mas1, 12.IV.2002, C. Rasmussen, ex nest inside "quina quina" [Ficus sp.] trunk, $2 \mathrm{~m}$ a[above] ground (2 ops., MUSM; 1 op., RPSP); ibidem, IXX.2002, Rasmussen, Rios (1 op., MUSM). Madre de Dios: Madre de Dios, 23.II.1962, Dourojeanni (2 ops., UNALM). BRASIL. Roraima: Caracarai-Rio Branco, NA-20, 61 ${ }^{\circ} 8^{\prime} \mathrm{W}, 1^{\circ} 5^{\prime} \mathrm{N}, 13-15$.VIII.1980, Camargo, Mazucato (48 ops., 32 machos, mais exemplares em fixador, ninho 272c, e 2 ops. s/n, RPSP); Ilha de Maracá, 5-10.X.1987, Lucio A. O. Campos, Marcos V. B. Garcia (5 ops., RPSP); ibidem, Alto Alegre, 20-26.VI.1988, Mielke, Mirna (1 op., DZUP). Amapá: Mazagão, 18.X.1900, Ducke, "P. Herbst Collection Ex Reed", "Trigona mocsaryi Friese, Det. Ducke, 1908" (1 op., CASC); Oiapoque, V.1959, M. Alvarenga (39 ops., SEMC; 16 ops., 1 macho, DZUP; 5 ops., RPSP); ibidem, VI.1959, F. V. Rodrigues (60 ops., DZUP); Porto Batom, 11.VII.1983, J. I. Lacerda (1 op., DZUP); Porto Platon, IX.1957, K. Lenko (1 op., DZUP); Serra do Navio, I.1957, Pereira, Machado (1 op., DZUP); ibidem, X.1957, K. Lenko (5 ops., 2 machos, DZUP); ibidem, 7.II.1962, F. M. Oliveira (1 op., DZUP); ibidem, XII.?, Bicelli (1 op., DZUP). Amazonas: Airão, rio Negro, 1.V.1949, Th. Dobzhansky (5 ops., DZUP); Alvarães, 645ㅇ'W, 3¹3'S, 24.VIII.1993, Camargo, Pedro, Mazucato (1 op., 936480, RPSP); Arimã, rio Purus, SB-20, 63² $1^{\prime} \mathrm{W}, 5^{\circ} 43^{\prime}$ S, 3-8.II.1986, Camargo, Mazucato (106 ops., mais exemplares em fixador, ninho $363 \mathrm{c} ; 58$ ops., ninho $371 \mathrm{c} ; 96$ ops., ninho 372c, e 6 ops., 861831-836, RPSP); Arumã, rio Purus, SB-20, 62 ${ }^{\circ}$ 'W, 4⒋ 'S, 15-16.II.1986, Camargo, Mazucato (98 ops., ninho $387 \mathrm{c}$, RPSP); B.A.B.A. $($ sic $=$ Bê-á-bá $)$, rio Purus, SB-20, 62 ${ }^{\circ} 53^{\prime} \mathrm{W}, 4^{\circ} 52^{\prime}$ 'S, 12-13.II.1986, Camargo, Mazucato (102 ops., ninho 380c; 104 ops., ninho 385c, e 1 op. s/n, RPSP); Cachoeira J. Bani, $3 \mathrm{Km} \mathrm{W}$, rio Negro, 66ำ $17^{\prime} \mathrm{W}, 0^{\circ} 22^{\prime}$ S, 5.VII.1999, Camargo, Pedro, Mazucato (30 ops., 995213-229, RPSP); Camanaus, rio Negro, SA19, 66 $54^{\prime} \mathrm{W}, 0^{\circ} 8^{\prime}$ 'S, 12-14.VII.1980, Camargo, Mazucato (50 ops., mais exemplares em fixador, ninho $210 \mathrm{c}$, RPSP); ibidem, $66^{\circ} 56^{\prime} \mathrm{W}$, $0^{\circ} 8$ 'S, 28-29.VI.1999, Camargo, Pedro, Mazucato (90 ops., ninho 726c; 90 ops., ninho $727 \mathrm{c} ; 2$ ops., 994040-41, RPSP); ibidem, $66^{\circ} 56^{\prime} \mathrm{W}$, 08'S, 28.VI.1999, G. A. R. Melo (1 op., DZUP); Camaruã, rio Purus,

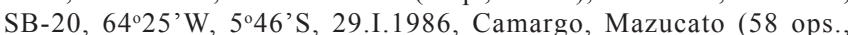
860874-892, 862561, RPSP); ibidem, $15 \mathrm{Km}$ à jusante, SB-20, $64^{\circ} 25^{\prime} \mathrm{W}, 5^{\circ} 40^{\prime} \mathrm{S}$, 31.I-1.II.1986, Camargo, Mazucato (102 ops., mais exemplares em fixador, ninho 360c, e 3 ops., 861163, 861272-273,

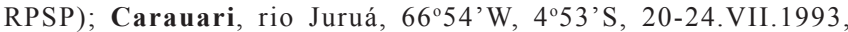
Camargo, Pedro, Mazucato (70 ops., mais exemplares em fixador, ninho 515c; 59 ops., 1 macho, ninho 530c, e 123 ops. 932847, 932851, 932855, 932856, 932858-982, 932984, RPSP); Castanheirinho, Aldeia Baniwa, rio Negro, 66¹7’W, 0²3'S, 5-6.VII.1999, Camargo, Pedro, Mazucato (83 ops., ninho $752 \mathrm{c}$, RPSP); Foz do Rio Curicuriari, rio Negro, SA-19, 66 $6^{\circ} 49^{\prime} \mathrm{W}, 0^{\circ} 13^{\prime} \mathrm{S}, 15-21$.VII.1980, Camargo, Mazucato (45 ops., ninho $217 \mathrm{c} ; 58$ ops., ninho $219 \mathrm{c} ; 40$ ops., ninho 228c, mais exemplares em fixador, RPSP); Foz do Rio Marié, rio Negro, SA-19, 66 ${ }^{\circ} 26^{\prime} \mathrm{W}, 0^{\circ} 26^{\prime}$ 'S, Camargo, Mazucato (7 ops., RPSP); Igarapé Maripá, rio Uatumã, SA-21, 575ㅗ' W, $2^{\circ} 33^{\prime}$ S, 22-23.II.1979, Camargo (41 ops., mais exemplares em fixador, ninho $205 \mathrm{c}$, mais 21 ops. s/n, RPSP); Lago Boari, rio Negro, $61^{\circ} 18^{\prime} \mathrm{W}$, 158'S, 2.VIII.1999, Camargo, Pedro, Mazucato (34 ops., 997851873, 997878, RPSP); Manaus, "Manaos", 9.VIII.1924, anônimo, "Trigona heideri mocsaryi Friese, Det. Schwarz" (1 op., RPSP); ibidem, VII.1958, C. Elias (4 ops., DZUP); ibidem, idem, V.1959 (12 ops., DZUP); ibidem, idem, VII.1959, (6 ops., DZUP); ibidem, idem, VIII.1959, (76 ops., 1 macho, DZUP); ibidem, idem, IX.1959 (1 op., DZUP); ibidem, idem, X.1959 (1 op., DZUP); ibidem, idem, I.1961 (39 ops., DZUP); ibidem, II.1955, I. Costa-Leite (2 ops., DZUP); ibidem, VII.1962, F. M. Oliveira (12 ops., DZUP); ibidem, Vila Careiro, 27.VI.1975, W. Kerr (4 ops., RPSP); ibidem, SA-20, 60-3c, 1.II.1976, 


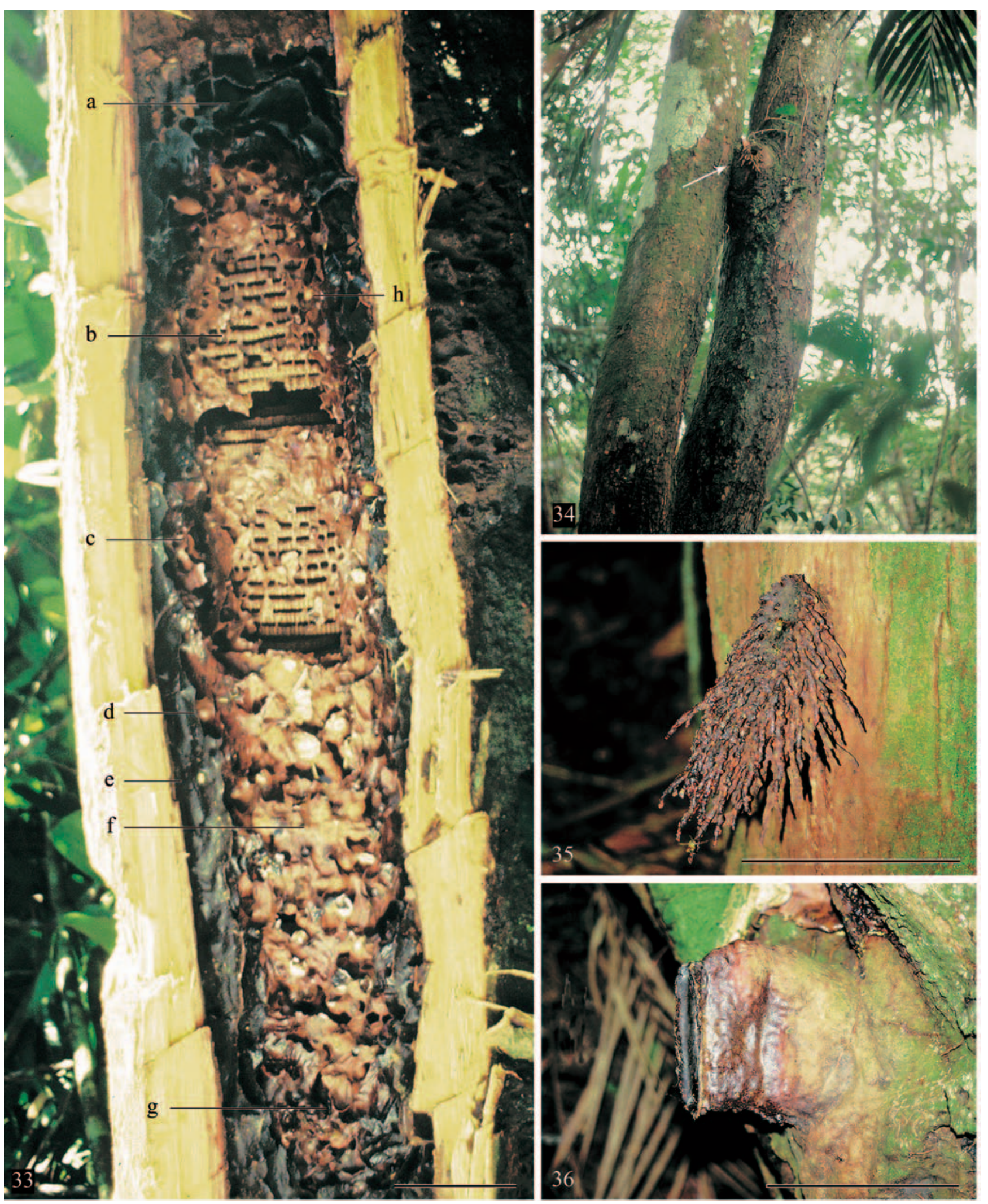

Figs. 33-36. Ptilotrigona, ninhos. 33-35. P. lurida: 33, ninho (Camanaus, rio Negro, AM, Brasil, ninho 210c), no interior de oco de árvore viva - a. batume superior, b. favos de cria, c. invólucro interno de cerume, d. pote de mel, e. invólucro externo de resinas, f. potes de pólen, g. potes de resinas, h. realeira; 34, a seta indica a localização da entrada de um ninho (Alter do Chão, PA, Brasil, ninho 170c), diâmetro do tronco, $30 \mathrm{~cm}$; 35, detalhe da entrada do ninho 727c (Camanaus, AM, Brasil); 36, P. pereneae, detalhe da entrada do ninho 517c (Carauari, rio Juruá, AM, Brasil). Escalas $=10,0 \mathrm{~cm}$. 
J. M. F. Camargo (3 ops., RPSP); ibidem, ZF2, Área de Exp. Ecológica (DEA-INPA), $14 \mathrm{Km}$ do Campus, 17.VI.1980, W. E. Kerr (1 op., RPSP); ibidem, 7.III.1982, E. F. Morato, INPA/WWF PDBFF 132 (1 op., DZUP); ibidem, idem, 3.III.1988, INPA/WWF PDBFF 188 (1 op., DZUP); ibidem, PDBFF, 5.XI.1989, M. L. Oliveira (5 ops., 900640644, RPSP); ibidem, 11.VIII.1991, G.A.R. Melo (1 op., DZUP); ibidem, idem, $60 \mathrm{Km} \mathrm{N}$, Faz. Esteio, $2^{\circ} 25^{\prime}$ 'S, 59 $50^{\prime} \mathrm{W}$, 18.VIII.1991, Colosso (1 op., DZUP); ibidem, $70 \mathrm{Km} \mathrm{N}, 59^{\circ} 46^{\prime} 12^{\prime \prime} \mathrm{W}, 2^{\circ} 27^{\prime} \mathrm{S}, 26-$ 31.VIII.1994, S. R. M. Pedro (62 ops., ninho 649c; 55 ops. ninho 654c, e 9 ops., 941207-209, 941211, 941216-219, 941227, RPSP); ibidem, 62 Km N, BR174, Km 45, 11-13.VIII.1994, S. R. M. Pedro (9 ops., 941255-257, 941339, 941341-142, RPSP); Manaus Itacoatiara, Areal, Km 64, 21.X.1977, J. Becher (4 ops., 922414-

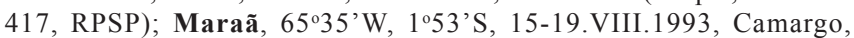
Pedro, Mazucato (60 ops., ninho 600c, e 58 ops., 935286-330, RPSP); Pai Raimundo, rio Demini, 62 ${ }^{\circ} 53^{\prime} \mathrm{W}, 0^{\circ} 24^{\prime}$ 'S, 23.VII.1999, Camargo, Pedro, Mazucato (85 ops., 1 macho, ninho 810c, RPSP); Plano, rio Negro, 65'59'W, 0¹8'S, 7-9.VII.1999, Camargo, Pedro, Mazucato (1 op., 995491, RPSP); Ponta do Gavião, rio Negro, $62^{\circ} 12^{\prime} \mathrm{W}, 1^{\circ} 18^{\prime} \mathrm{S}$, 29-31.VII.1999, Camargo, Pedro, Mazucato (5 ops., 997809-813, RPSP); Praia Grande, rio Negro, 60³2'W, $3^{\circ} 2^{\circ}$ 'S, 18.VIII.1994, S. R. M. Pedro (81 ops., 941105-143, 941145, 941148, 941303-311, 941314-329, RPSP); Reserva Ducke, 12.V.1981, D. W. Roubik (2 ops., STRI); ibidem, idem, 12.V.1982 (1 op., STRI); ibidem, idem, 12.V.1983 (1 op., STRI); ibidem, idem, 12.V.1984 (1 op., STRI); ibidem, idem, 12.V.1985 (1 op., STRI); Rio Ipixuna, rio Purus, SB20, 63 ${ }^{\circ} 20^{\prime} \mathrm{W}, 6^{\circ} 0^{\prime} \mathrm{S}, 20-23 . I .1986$, Camargo, Mazucato (2 ops., 860339, 860688, RPSP); Rio Paranaí (?), 3.37 (III.1937?), anônimo (1 op., DZUP); Santa Isabel, rio Negro, $0^{\circ} 25^{\prime} \mathrm{S}, 65^{\circ} 01^{\prime} \mathrm{W}$, 11.VII.1999, G. A. R. Melo (1 op., DZUP); Samaúma, rio Daraã, 64ㄴ5' W, 0²6'S, 17-20.VII.1999, Camargo, Pedro, Mazucato (32 ops., 996880-899, RPSP); Samaúma, rio Demini, 62 ${ }^{\circ} 46^{\prime} \mathrm{W}, 0^{\circ} 22^{\prime} \mathrm{S}$, 24.VII.1999, Camargo, Pedro, Mazucato (83 ops., 1 macho, mais exemplares em fixador, ninho 811c, e 11 ops., 997068-073, RPSP); Santa Eutália, rio Juruá, $63^{\circ} 35^{\prime}$ W, 45ㄱ'S, 20-26.VII.1993, Camargo, Pedro, Mazucato (60 ops., ninho 532c, RPSP); São Jorge, rio Curicuriari, 66 $50^{\circ} \mathrm{W}, 0^{\circ} 13^{\prime} \mathrm{S}, 26-27 . \mathrm{VI} .1999$, Camargo, Pedro, Mazucato (85 ops. mais exemplares em fixador, ninho 722c, e 19 ops., 993389-395, 993492-500, 994039-041, RPSP); São Paulo de Olivença, SA-19, 69-4b, 19-20.I.1977, Camargo, Mazucato (1 op., RPSP); Tabocal, rio Uneiuxi, 656' $\mathrm{W}, 0^{\circ} 35^{\prime}$ 'S, 13-15.VII.1999, Camargo, Pedro, Mazucato (71 ops., ninho $785 \mathrm{c}$, RPSP); Tapera, lago Caurés, rio Negro, $62^{\circ} 11^{\prime} \mathrm{W}, 1^{\circ} 19^{\prime}$ 'S, 27-28.VII.1999, Camargo, Pedro, Mazucato (90 ops., ninho 820c, RPSP); Tapurucuara [= Santa Isabel do Rio Negro], VII.1962, F. M. Oliveira (144 ops., DZUP); Tapurucuara-mirim, rio Negro, 66 ${ }^{\circ} 24^{\prime} \mathrm{W}, 0^{\circ} 25^{\prime} \mathrm{S}, 1-4$.VII.1999, Camargo, Pedro, Mazucato (70 ops., ninho 745 c, e 57 ops. e 3 machos, 994875-908, 995063, 995079, RPSP); Tefé, 15.XII.1961, F. M. Oliveira (2 ops., RPSP); ibidem, idem, XII.1961 (1 op., DZUP); ibidem, "Teffé", 7.IX.1904, Ducke, "Melipona (Trig.) heideri Fr. v. mocsaryi Fr. det. Ducke 1914", “Tr. heideri, 1925 Friese det." (1 macho, AMNH); Uaupés [=São Gabriel da Cachoeira] VII.1956, M. Alvarenga (2 ops., DZUP); Vendaval, SA-19, 69-3, h-VI, 16-18.I.1977, Camargo, Mazucato (1 op., AMNH; 1 op., SEMC; 115 ops. s/n e 35 ops., ninho 62c, RPSP); Vila Nova do Tonantins, SA-19, 68-3f.IX, 22-23.I.1977, Camargo, Mazucato (35 ops., ninho 90c, RPSP). Pará: Alter do Chão, rio Tapajós, SA-21, 545ㄱ'W, 2³0'S, 3-4.II.1979, Camargo (35 ops., 5 machos, mais exemplares em fixador, ninho 170c, RPSP); Aurá [Belém], 16.VI.1956, E. Lobato (1 op., DZUP); Barreirinha, rio Tapajós, 21.XI.1970, Exp. Perm. Amaz. (51 ops., DZUP); Belém, Mangabeira, IX-X.1940, anônimo (1 op., DZUP); ibidem, Brasil norte, 8-10.V.1949, Th. Dobzhansky, "Trigona testacea Spinola Det. J. S. Moure 58" [prov. exemplar marcado como referência, em relação ao tipo, por Moure] (1 op., DZUP); ibidem, idem, 8-10.VII.1949, (1 op., DZUP); ibidem, 17.VIII.1954, N. Cerqueira, "Ptilotrigona (Sm) Pe. J. S. Moure 1984" (1 op., DZUP); ibidem, 28.VI.1956, E. Lobato (3 ops., DZUP); ibidem, 5.X.1972, Kerr (180 ops., mais exemplares em fixador, ninho 29c, RPSP); ibidem, Ariboca, 21.XI.1955, Michener, Moure (1 op., SEMC); ibidem, idem, 24.XI.1955 (4 ops., DZUP); Benfica, 4.VI.1961, O. L. M. Rego (1 op., DZUP); Cachimbo,
IX.1954, M. Alvarenga (3 ops., SEMC; 51 ops., 1 macho, DZUP); ibidem, idem, 6.I.1955 (1 op., DZUP); ibidem, idem, X.1959 (1 op., DZUP); ibidem, VI.1962, M. Alvarenga, F. M. Oliveira (3 ops., SEMC); Cachoeira da Porteira, rio Trombetas, SA-21, 57 ${ }^{\circ}$ ' W, $1^{\circ} 4^{\prime}$ S, 912.II.1979, Camargo (2 ops., AMNH; 1 op., SEMC; 26 ops. ninho 174 c; 30 ops., mais exemplares em fixador, ninho 180 c, e 39 ops. s/n, RPSP); Gorotire (=Gradaús), SB-22, 51-8a, 20.VIII-5.IX.1983, Camargo (18 ops., 831248-252, 831254, 831264, 831266, 831269, 831273, 831275, 831279-281, 831285-286, 831290, 831292, RPSP); Gradaús, 51 ${ }^{\circ}$ 'W, $7^{\circ} 48^{\prime} \mathrm{S}, 1978$, Posey (1 op., RPSP); Jacareacanga, X.1959, M. Alvarenga (2 ops., SEMC); Lago Carimum, rio Trombetas, SA.21-x-c, 56 $6^{\prime}$ W, 1'32's, 16-17.II.1979, Camargo (1 op., RPSP); Óbidos, 20.VII.1902, Ducke, "P. Herbst Collection Ex Reed", "T. mocsaryi, 1900 Friese, det. Fr." (1 op., CASC); ibidem, idem, 20.VII.1902, "P. Herbst Collection Ex Reed", "Trigona mocsaryi, Det. Ducke, 1908" (1 op., CASC); ibidem, XII.1937, anônimo (1 op., DZUP); ibidem, VIII.1953, J. Brazillino (1 op., EMEC); ibidem, idem, V.1954 (16 ops., SEMC; 2 ops., EMEC; 6 ops., DZUP; 2 ops., RPSP); ibidem, idem, IX.1954, "Ptilotrigona lurida (Sm.), Pe. J. S. Moure 1984" [etiq. de identificação em apenas um exemplar] (4 ops., DZUP); ibidem, X.1954, F. M. Oliveira (4 ops., DZUP); ibidem, idem, 1962 (1 op., DZUP); Pará [sem localidade especificada], "Pará, Brasil, Baker", 20.IX.1899, Ducke, "P. Herbst Collection Ex Reed", "Trigona heideri Friese, Det. Ducke 1908" (1 op., CASC); ibidem, idem, V.1901, "Trigona heideri, 1904 Friese, det. Fr." (1 op., LACM); ibidem, idem, 7.VIII.1900, "Cornell U. lot 546, sub. 676 Baker coll.", "Trigona heideri, 1904 Friese, det. Fr." (1 op., AMNH); ibidem, idem, I. 1900 "Am. Mus. Nat. Hist. Dept. Invert. Zool. no. 28102", "Trigona heideri, 1904 Friese, det. Fr." (1 op., AMNH); ibidem, idem, sem data (1 op., LACM; 7 ops., USNM, 2 delas com etiq. adicional vermelha: "TYPUS", e etiq. manuscrita de Friese "Trigona heideri, 1911 Friese, det. Fr.", não pertencem à série-tipo original); ibidem, idem, sem data, "8216", etiq. de cor salmão: "TYPUS", etiq. manuscrita de Friese: "Trigona heideri, 1911 Friese, det. Fr." - não pertence à série-tipo original (1 op., AMNH); Paragominas (30 Km S), SA-23, 47II-3g, 11.II.1984, Camargo, Mazucato (19 ops., 840010-019, 840021-024, 840027-031, RPSP); Rio Moju, X.1954, R. Damasceno (2 ops., DZUP); Santarém, sem data, anônimo, "Trigona (Tetragona) heideri var. heideri Friese, Det. H. F. Schwarz" (2 ops., AMNH); Tauari, rio Tapajós, SA-21,

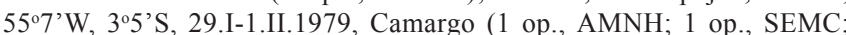

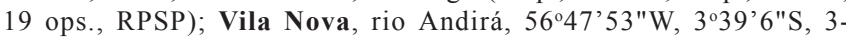
5.II.2001, J. M. F. Camargo (56 ops., ninho 869c, RPSP). Acre: Brasiléia, B. [?] Porongaba, 30.X.1993, M. L. Oliveira (2 ops., RPSP); Plácido de Castro, 10.X.1989, Dain (4 ops., 900083-086, RPSP); Rio Branco, 15-20.XI.1961, F. M. Oliveira (1 op., DZUP). Rondonia: Campo Novo, BR-421, oeste de C.N., 635'' W, 10²7'S, 11.IX.1997, Brown, Boina, Vieira (1 op., RPSP); ibidem, idem, BR-421, Rio JaciParaná, 64ำ' W, 10²6'S, 11.IX.1997 (5 ops., RPSP); Cerejeiras,

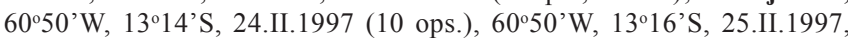
Brown, Boina, Vieira (4 ops., RPSP); Chupinguaia, $61^{\circ} 10^{\prime} \mathrm{W}, 12^{\circ} 32^{\prime} \mathrm{S}$, 22.II.1997, Brown, Boina, Vieira (1 op., RPSP); Costa Marques / Guajará Mirim, Estrada 478, 64²0’W, 12²6’'S, 19.XI.1996 (2 ops.), $64^{\circ} 1^{\prime} \mathrm{W}, 12^{\circ} 17^{\prime} \mathrm{S}, 21 . X I .1996$ ( 1 op.), $64^{\circ} 22^{\prime} \mathrm{W}, 12^{\circ} 6^{\prime} \mathrm{S}, 22 . X I .1996$

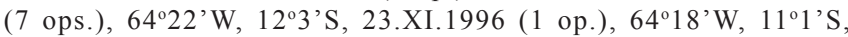

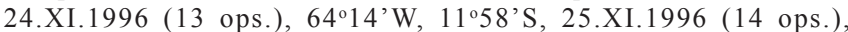

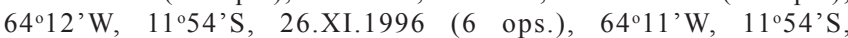
26.XI.1996, Brown, Boina, Vieira (3 ops.; RPSP); Cujubim, Reserva Rio Cujubim, 62 $34^{\prime} \mathrm{W}, 9^{\circ} 20^{\prime}$ 'S, 24.III.1997, Brown, Boina, Vieira (22 ops., 11 machos, RPSP); ibidem, idem, Linha 14, 62 $2^{\circ} 33^{\prime} \mathrm{W}, 9^{\circ} 20^{\prime} \mathrm{S}$, 24.III.1997 (8 ops., RPSP); ibidem, idem, Linha C2, 62'34'W, 9'23'S, 25.III.1997 (14 ops., RPSP); ibidem, idem, Linha 46, 62³3'W, 9'24'S, 25.III.1997 (2 ops.), 62³6' W, 9²0'S, 26.III.1997 (1 op.; RPSP); Extrema, Linha 4, 66 $26^{\prime}$ W, 944'S, 26.VI.1997, Brown, Boina, Vieira (1 op., RPSP); Guajará Mirim, Pacaás Novos, 24.IV.1995, M. L. Oliveira (6 ops., RPSP); ibidem, idem, 20.I.1996 (1 op., RPSP); ibidem,

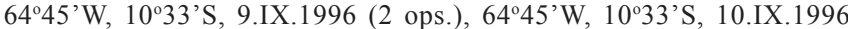

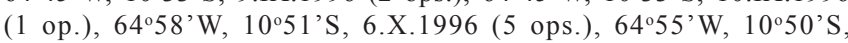

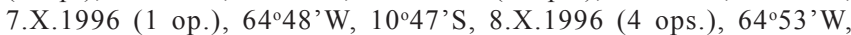

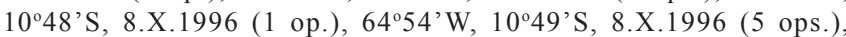

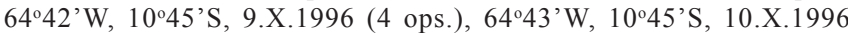



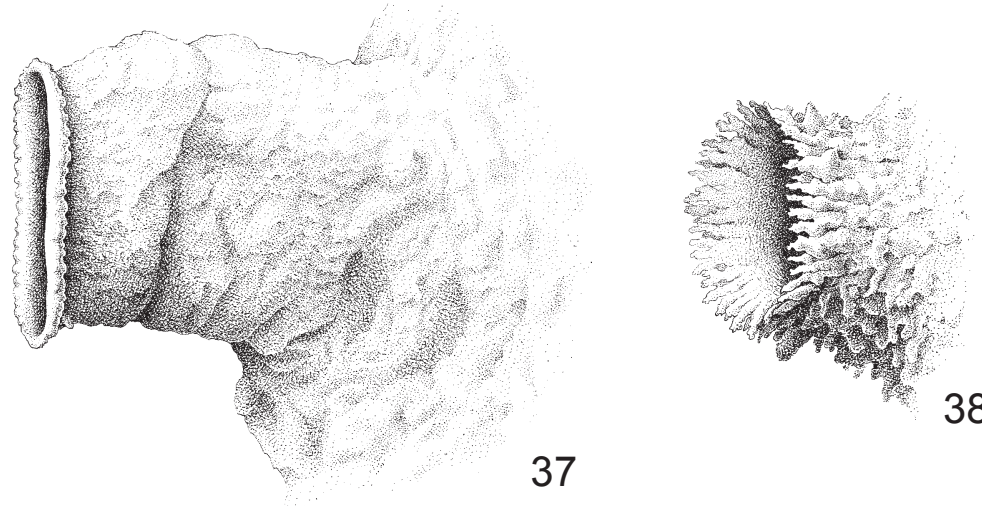

38

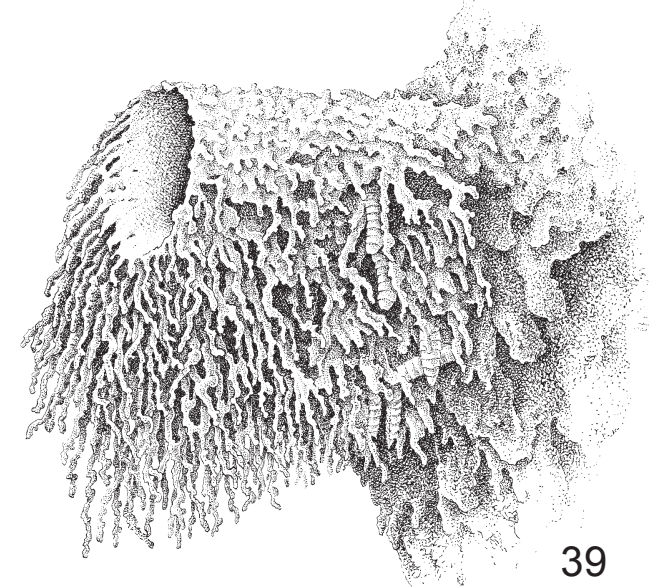

Figs. 37-39. Ptilotrigona, entrada de ninhos: 37, P. pereneae (Carauari, rio Juruá, AM, Brasil, ninho 517c); 38, P. lurida (15 Km a jusante de Camaruã, rio Purus, AM, Brasil, ninho 360c); 39, P. lurida (Camanaus, AM, Brasil, ninho 210c); inseridas na trama radiculiforme, vêem-se alguns pupários de Stratiomyidae. Escala $=5,0 \mathrm{~cm}$.

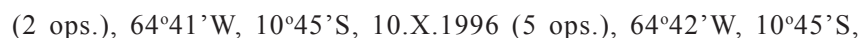

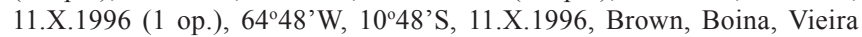

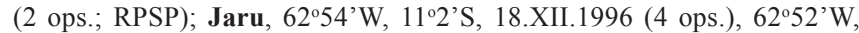
$11^{\circ} 1^{\prime}$ S, 7.I.1997, Brown, Boina, Vieira (10 ops.; RPSP); Machadinho, Linha 32, 61²49'W, 9²3'S, 20.III.1997, Brown, Boina, Vieira (6 ops.); ibidem, idem, Estrada 133 a Tabajara, 62³'W, 9³'S, 22.III.1997, (5 ops., RPSP); Mirante da Serra, 62 ${ }^{\circ} 50^{\prime} \mathrm{W}, 10^{\circ} 59^{\prime}$ 'S, 24.IX.1996 (7

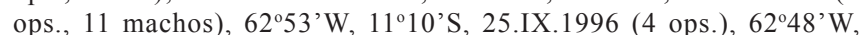



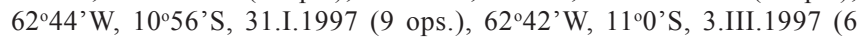
ops.), 62 ${ }^{\circ} 54^{\prime} \mathrm{W}, 11^{\circ} 4^{\prime}$ 'S, 4.III.1997, Brown, Boina, Vieira (13 ops.,

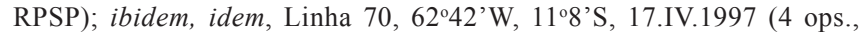

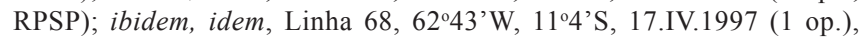
$62^{\circ} 47^{\prime} \mathrm{W}, 11^{\circ} 0$ 'S, 19.VIII.1997 (2 ops.; RPSP; 1 op., RO 13248, SEMC); ibidem, idem, Linha 76, 62 $2^{\circ} 8^{\prime} \mathrm{W}, 11^{\circ} 7^{\prime} \mathrm{S}, 18 . \mathrm{IV} .1997$ (10 ops.), $62^{\circ} 50^{\prime} \mathrm{W}, 11^{\circ} 5^{\prime} \mathrm{S}, 30 . \mathrm{VIII} .1997$ (6 ops.; RPSP); ibidem, idem, Linha 62, 62 ${ }^{\circ} 39^{\prime} \mathrm{W}, 11^{\circ} 3^{\prime} \mathrm{S}, 15 . \mathrm{V} .1997$ (9 ops., RPSP); ibidem, idem, Linha 66, 62 ${ }^{\circ} 43^{\prime} \mathrm{W}, 11^{\circ} 5^{\prime}$ 'S, 15.V.1997 (1 op., RPSP); ibidem, idem, Linha

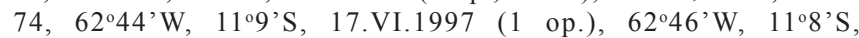
21.VIII.1997 (4 ops.; RPSP); ibidem, idem, Linha $80,62^{\circ} 55^{\prime} \mathrm{W}, 11^{\circ} 3^{\prime} \mathrm{S}$,

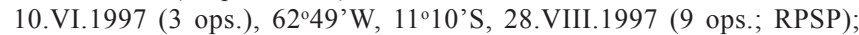
ibidem, idem, Linha 78, 62 ${ }^{\circ} 46^{\prime} \mathrm{W}, 11^{\circ} 10^{\prime} \mathrm{S}, 17 . \mathrm{VI} .1997$ (5 ops.), $62^{\circ} 45^{\prime} \mathrm{W}, 11^{\circ} 10^{\prime} \mathrm{S}, 28$.VIII.1997 (4 ops.; RPSP); ibidem, idem, Linha 52, 62 $2^{\circ} 40^{\prime} \mathrm{W}, 10^{\circ} 56^{\prime} \mathrm{S}, 14$.VIII.1997 (2 ops., RPSP); ibidem, idem, Linha 60, 62 ${ }^{\circ} 43^{\prime} \mathrm{W}, 11^{\circ} 0^{\prime} \mathrm{S}, 15 . \mathrm{VIII} .1997$ (3 ops., RPSP); ibidem,

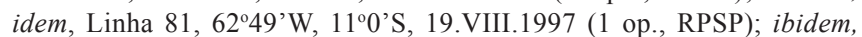
idem, Linha 72, 62 ${ }^{\circ} 52^{\prime} \mathrm{W}, 11^{\circ} 0^{\prime} \mathrm{S}, 20 . \mathrm{VIII} .1997$ (5 ops., RPSP); ibidem, idem, Linha $84,62^{\circ} 53^{\prime} \mathrm{W}, 11^{\circ} 8$ 'S , 29 .VIII.1997 (8 ops., RPSP); Nova

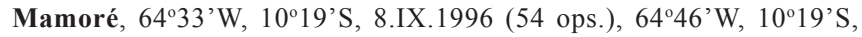
12.IX.1996, Brown, Boina, Vieira (17 ops.; RPSP); Nova União,



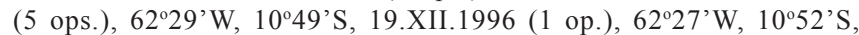

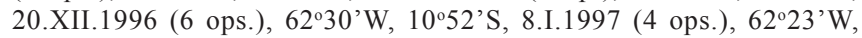
$10^{\circ} 51$ 'S, 8.III.1997, Brown, Boina Vieira (2 ops.; RPSP); ibidem, idem, Linha $40,62^{\circ} 32^{\prime} \mathrm{W}, 10^{\circ} 54^{\prime} \mathrm{S}, 14 . \mathrm{V} .1997$ (3 ops.), $62^{\circ} 28^{\prime} \mathrm{W}, 10^{\circ} 55^{\prime} \mathrm{S}$, 14.V.1997 (7 ops.), 6240'W, 1050'S, 1.IX.1997 (1 op.; RPSP); ibidem, idem, Linha $28,62^{\circ} 26^{\prime} \mathrm{W}, 10^{\circ} 55^{\prime} \mathrm{S}, 12$.VII.1997 (4 ops., RPSP);

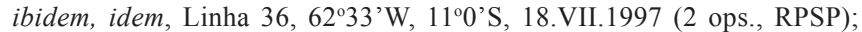
ibidem, idem, Linha $24,62^{\circ} 25^{\prime} \mathrm{W}, 10^{\circ} 50^{\prime} \mathrm{S}, 31$.VII.1997 (2 ops., RPSP); ibidem, idem, Linha $28,62^{\circ} 27^{\prime} \mathrm{W}, 10^{\circ} 50^{\prime} \mathrm{S}$, 1.VIII.1997 (1 op., RPSP); ibidem, idem, Linha 32, 62 $29^{\prime} \mathrm{W}, 10^{\circ} 52^{\prime}$ 'S, 4 .VIII.1997 (2 ops., RPSP); ibidem, idem, Linha 36, 62³6'W, 1048'S, 1.IX.1997 (1 op., RPSP); Ouro Preto d'Oeste, 19.VIII.1987, C. Elias, "Projeto Polonoroeste"
(1 op., DZUP); ibidem, idem, 18.X.1987 (7 ops., DZUP); ibidem, idem, 29.X.1987 (8 ops., DZUP); ibidem, idem, 15.III.1988 (12 ops., DZUP); ibidem, $62^{\circ} 19^{\prime} \mathrm{W}, 10^{\circ} 41^{\prime} \mathrm{S}, 17 . X I I .1996$ (6 ops.), $62^{\circ} 18^{\prime} \mathrm{W}$, $10^{\circ} 44^{\prime}$ 'S, 9.I.1997 (5 ops.), 62²2'W, $10^{\circ} 42^{\prime}$ 'S, 10.I.1997 (1 op.),

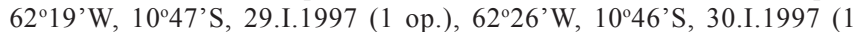
op.), $62^{\circ} 23^{\prime} \mathrm{W}, 10^{\circ} 48^{\prime} \mathrm{S}, 30 . \mathrm{I} .1997$ (3 ops.), $62^{\circ} 18^{\prime} \mathrm{W}, 10^{\circ} 43^{\prime} \mathrm{S}$, 14.IV.1997, Brown, Boina, Vieira (1 op.; RPSP); ibidem, idem, Linha $16,62^{\circ} 19^{\prime} \mathrm{W}, 10^{\circ} 50^{\prime} \mathrm{S}, 15 . \mathrm{IV} .1997$ (2 ops.), 62 $28^{\prime} \mathrm{W}, 10^{\circ} 40^{\prime} \mathrm{S}$, 21.VI.1997 (11 ops.; RPSP); ibidem, idem, Linha 12, 62 $18^{\prime} \mathrm{W}, 10^{\circ} 49^{\prime} \mathrm{S}$, 15.IV.1997 ( 2 ops.), 62 $12^{\circ} \mathrm{W}, 10^{\circ} 47^{\prime} \mathrm{S}, 13 . \mathrm{V} .1997$ (4 ops.; RPSP);

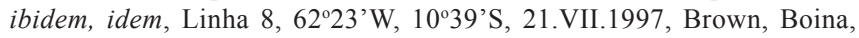
Vieira (1 op., RPSP); Pimenta Bueno, XI.1960, M. Alvarenga (3 ops., SEMC; 2 ops., DZUP); Pimenteiras, $61^{\circ} 24^{\prime} \mathrm{W}, 12^{\circ} 40^{\prime} \mathrm{S}$, 19.II.1997, Brown, Boina, Vieira (1 op. RPSP); Porto Velho, rio Madeira, sem data, Mann \& Baker, Type $\mathrm{n}^{\circ} 23256$ USNM [etiq. vermelha], "Trigona manni Ckll. TYPE" [etiq. manuscrita], "Trigona manni = heideri (Ck1l. 1920)" [etiq. manuscrita] (Cockerell refere-se a dois exemplares do rio Madeira, mas designa apenas um deles como "type", = holótipo) (1 op., USNM); ibidem, Guaporé, IX.1954, M. Alvarenga, Dente, F. Pereira, Werner (2 ops., DZUP); ibidem, XII.1954, M. Alvarenga (10 ops., SEMC; 1 op., DZUP); ibidem, 12-22.X.1966, Camargo (2 ops., AMNH; 2 ops., SEMC; 47 ops., RPSP); ibidem, Estação Ecológica Cuniã, 6332'W, 8²3'S, 22.V.1997 (19 ops.),

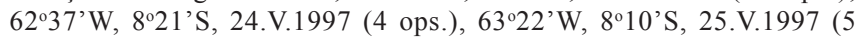
ops.), $63^{\circ} 22^{\prime} \mathrm{W}, 8^{\circ} 10^{\prime} \mathrm{S}, 25 . \mathrm{V} .1997$ (5 ops.), 66 $6^{\circ} 33^{\prime} \mathrm{W}, 8^{\circ} 21^{\prime} \mathrm{S}$, 26.V.1997, Brown, Boina, Vieira (4 ops.; RPSP); Rolim de Moura,

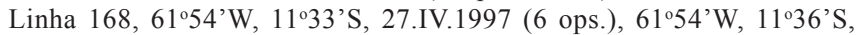
27.IV.1997, Brown, Boina, Vieira (3 ops.; RPSP); São Miguel do Guaporé, Linha $25,62^{\circ} 44^{\prime} \mathrm{W}, 11^{\circ} 43^{\prime}$ S, 20.IV.1997, Brown, Boina, Vieira (12 ops., RPSP); ibidem, idem, Linha $82,62^{\circ} 43^{\prime} \mathrm{W}, 11^{\circ} 46^{\prime} \mathrm{S}$, 20.IV.1997 (10 ops., RPSP); ibidem, idem, Reserva Indígena Rio Branco, 62 ${ }^{\circ} 43^{\prime} \mathrm{W}, 1^{\circ} 56^{\prime}$ 'S, 23.IV.1997 (8 ops., RPSP); Vilhena, 13.XI.1986, C. Elias, Polonoroeste (27 ops., DZUP). Maranhão: Buriticupu, 20


ops. e machos em fixador, ninho 679c, e 2 ops., 941715-732, RPSP); Chapadinha, $43^{\circ} 21^{\prime} \mathrm{W}, 3^{\circ} 44^{\prime}$ 'S, 11.XI.1994, Camargo, Pedro (120 ops., mais exemplares em fixador, ninho 664c, RPSP); Imperatriz, I.1973, "Excursão Ex. Dpto. Zool.", "UFPA" (3 ops., DZUP); ibidem, idem, $39 \mathrm{Km} \mathrm{S}, 43^{\circ} 30^{\prime} \mathrm{W}, 5^{\circ} 5^{\prime} \mathrm{S}, 12-13 . I X .1994$ (13 ops., 941528530, 941579-588, RPSP); Nova Olinda, SA-23, 46.VI-3f, 15.II.1984, Camargo, Mazucato (65 ops., 840057, 840059-080, RPSP). Piauí: BR 316, km 132, Teresina - Picos, 14.IX.1979, M. J. G. Hopkins, H. C. Hopkins (1 op., RPSP). Mato Grosso: Barracão Queimado, 
XI.1960, M. Alvarenga (2 ops., DZUP); Mato Grosso, 2.XI.1961, F. M. Oliveira (1 op., DZUP; 3 ops., RPSP); Nhambiquaras, XI.1960, M. Alvarenga (1 op., SEMC); Nova Mutum, Faz. Buriti, 9.I.2000, H. F. Mendes (5 ops., 000091-095, RPSP); ibidem, idem, rio Arinos, 14.I.2000, (2 ops., 000101-102, RPSP); ibidem, idem, $40 \mathrm{Km} \mathrm{W}$, rio Arinos, 14.I.2000 (2 ops., DZUP); ibidem, rio Arinos, 1354'S, $56^{\circ} 21^{\prime} \mathrm{W}, 300 \mathrm{~m}, 19 . \mathrm{VII} .2000$, S. Mateus (1 op., DZUP). BOLÍVIA. La Paz: Coroico, 20.I.1953, anônimo (1 op., DZUP).

Distribuição geográfica. Matas da Amazônia - Colômbia, Equador, Peru, Bolívia e Brasil-, Venezuela, Guianas e Suriname (Fig. 46).

Nidificação - substrato e hábitat. Ao todo, foram estudados 38 ninhos ao longo da Amazônia brasileira, conforme relação no item "Material examinado" e localidades indicadas na Fig. 47. Vários desses ninhos foram totalmente abertos para estudo das estruturas internas.

Ptilotrigona lurida é uma das espécies de Meliponini mais conspícuas das matas de várzea, de igapós e de terra firme da Amazônia; nidifica, usualmente, em ocos de árvores vivas em lugares sombreados dentro da mata. É mais comum se encontrarem ninhos entre 1 e $3 \mathrm{~m}$ de altura, mas também podem ocorrer próximos ao rés-do-chão ou em pontos altos nos troncos, a 10-15 m de altura. Nas matas de várzea e de igapós, são sempre encontrados a pelo menos 1 ou $2 \mathrm{~m}$ acima do nível da cheia dos rios. Alguns ninhos podem ser vistos em ocos de palmeiras e em troncos secos, em pé ou caídos, mas a preferência é por árvores vivas. Nunca foi encontrado mais do que um ninho de $P$. lurida em uma mesma árvore, e os mais próximos vistos, em Chapadinha, MA, estavam a cerca de 200 m um do outro; mas não é incomum encontrá-la em ocos de árvores compartilhados com outras espécies de Meliponini. $\mathrm{O}$ ninho 600c, de Maraã, AM, estava instalado em um oco de tronco onde havia, também, cinco ninhos de Scaptotrigona sp., e um outro ninho, não numerado, de Chapadinha, MA, encontrava-se em uma árvore (Salvertia convallariodora St. Hil., Vochysiaceae) onde havia seis outros ninhos de diferentes espécies de Meliponini [Scaptotrigona sp., Tetragona clavipes (Fabricius, 1804), Trigona pallens (Fabricius, 1798) e Melipona compressipes fasciculata Smith, 1854] instalados em ocos no tronco e galhos. $\mathrm{O}$ diâmetro preferido dos ocos varia, em geral, entre 20 e $30 \mathrm{~cm}$. A maior parte dos ninhos estudados tinha entre 0,80 e 1,20 m de extensão, mas alguns eram muito grandes, chegando a ca. de 1,80 m de extensão por 20-25 cm de diâmetro, e muito populosos, com 15.000 a 30.000 indivíduos adultos (ver adiante, dados sobre número de favos e células).

$\mathrm{Na}$ Amazônia, além do nome popular "abelha-piranha", também é conhecida como "aramá" ou "araman", "borá-boi”, "borá-cavallo", ou "borá" apenas, de acordo com Ducke (1916b: 67).

Estrutura de entrada. Há uma considerável variação na forma da estrutura de entrada. Na região do baixo Tapajós Andirá e ao longo da região ao norte dos rios Amazonas e Japurá - Negro, predominam tubos de entrada ornamentados com um emaranhado de projeções radiculiformes (Figs. 35, 39, $47)$, enquanto na região ao sul do rio Solimões, a oeste do rio Madeira, predominam tubos mais simples, com poucas projeções radiculiformes, mais restritas ao bordo apical (Figs. $38,47)$. Em um dos ninhos vistos em Chapadinha, MA (664c), o tubo de entrada era muito curto e estreito $(0,8 \mathrm{~cm}$ de comprimento e a boca com $1,2 \mathrm{~cm}$ de altura por $2,0 \mathrm{~cm}$ de largura), e com apenas três pequenas projeções no bordo inferior. Os tubos, e também as projeções radiculiformes, são construídos com resinas, praticamente puras, enegrecidas, muito endurecidas e não pegajosas (não solúveis em éter etílico, terebintina e acetato de etila, e fracamente solúveis em benzina); às vezes, nota-se pequenas partículas de quartzo, pedaços de anteras e outras partículas vegetais entremeadas à resina. As projeções radiculiformes ao redor do tubo, principalmente na parte inferior, chegam a atingir $10 \mathrm{~cm}$ de comprimento por 2 a 7 mm de diâmetro, muito rústicas, anastomosadas e quebradiças. Em algumas entradas pode haver centenas de projeções (Figs. $35,39,47)$, formando grosso emaranhado, que serve, às vezes, de abrigo para pequenas aranhas, pupas de dípteros (Stratiomyidae, cujas larvas, às vezes, são encontradas no interior dos ninhos) e outros pequenos artrópodes; com o envelhecimento, adquirem uma coloração marrom-enegrecida ou pardo-enegrecida. Os tubos mais longos atingem ca. $15 \mathrm{~cm}$ de comprimento por ca. 4,5 cm de altura e 2,5-3,0 cm de largura internamente. A superfície interna do tubo é relativamente bem polida e alisada; no interior do oco, prolonga-se em uma galeria, com o mesmo diâmetro da entrada, com grossas paredes de resinas pretas, terminando ao lado da região de crias.

Comentários sobre o significado taxonômico dessa variação geográfica na forma da estrutura de entrada, são apresentados no item "Discussão" (p. 370).

Estruturas internas. As paredes do oco são, usualmente, impermeabilizadas com aplicações de resinas enegrecidas, formando um revestimento bem uniforme, e todo o ninho (Fig. 33 ) é envolvido por 1-3 lamelas constituídas de resinas negras, muito endurecidas, não pegajosas, com 2-3 mm de espessura cada uma. Essas lamelas são separadas, uma da outra, e da parede do oco, por espaços de 1-1,5 cm, e interligadas entre si e à parede por inúmeros conectivos, também constituídos de resinas negras. Na parte superior e, principalmente, na parte inferior do ninho, as lamelas são em maior número, podendo chegar a 7-8 camadas ou mais, e são mais espessas, com 3-4 mm cada uma. No limite inferior do ninho há, às vezes, um batume adicional, do mesmo material daquele das lamelas, com 4-5 mm de espessura, vedando todo o oco, com ou sem orifícios de drenagem.

Mais internamente há 2-3 finas lamelas de invólucro envolvendo todo o conjunto de favos, e, diferentemente daquelas do envoltório externo, são constituídas de cerume marrom-castanho, moles e frágeis.

Os favos de cria ocupam a parte superior central do ninho; são dispostos em camadas horizontais, superpostas ou em espiral, com espaços de 4-4,5 mm entre elas; geralmente estão separados em 2 a 6 conjuntos ou mais, cada conjunto com 10- 

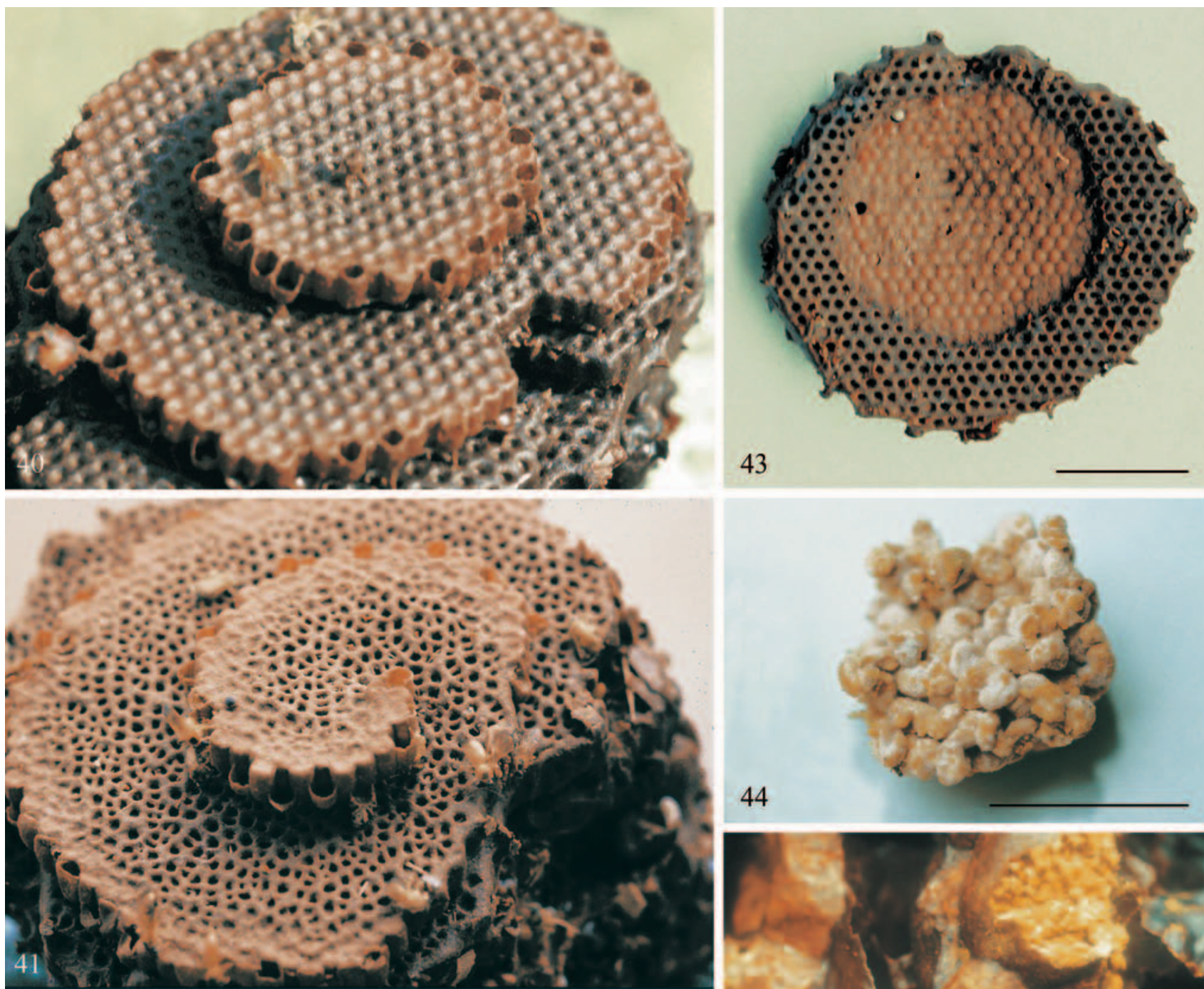

44
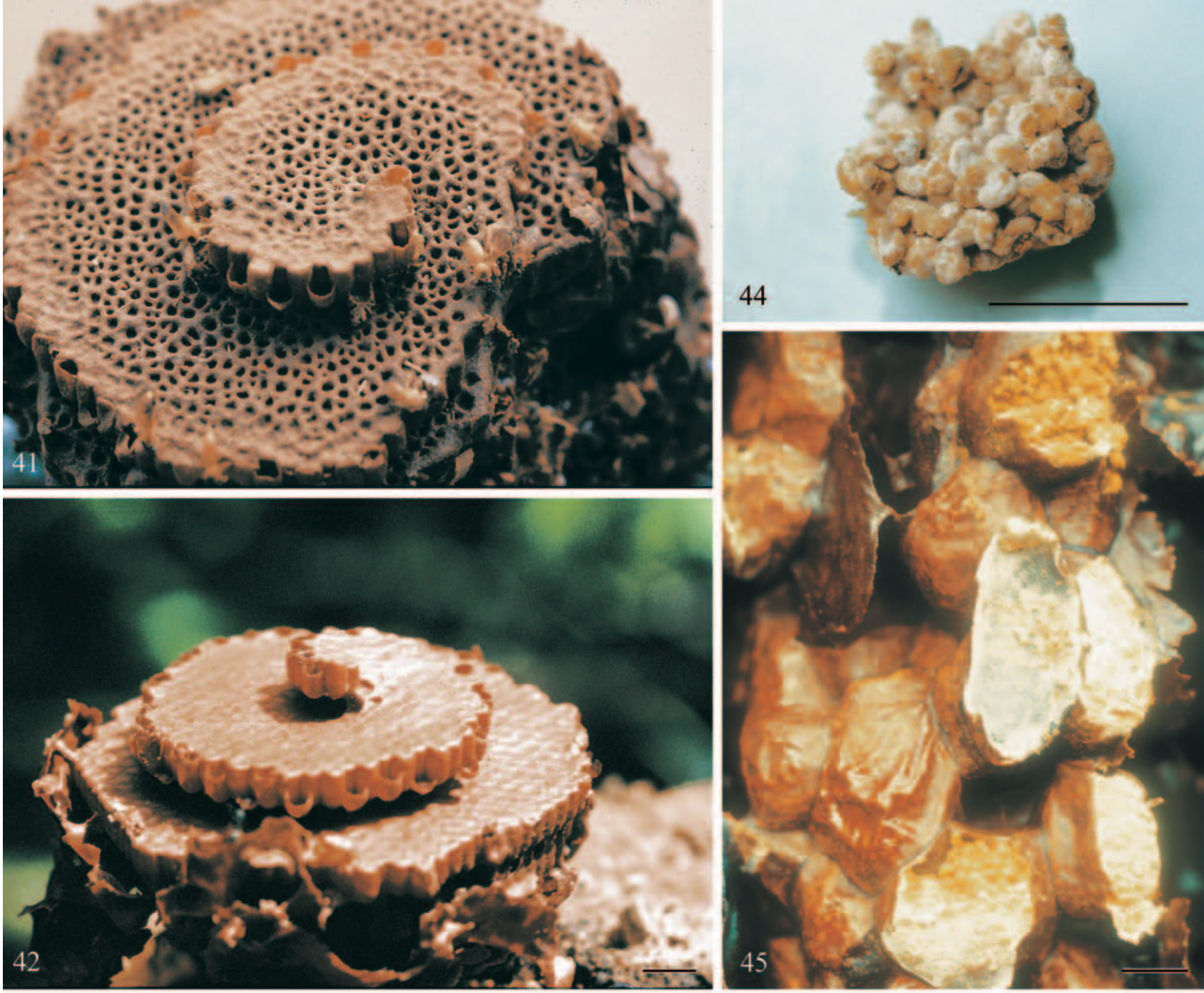

Figs. 40-45. Ptilotrigona lurida, detalhes dos favos e potes de pólen: 40, favos com rebaixos regulares no topo das células (Curicuriari, rio Negro, AM, Brasil, ninho 217c); 41, favos com rebaixos irregulares no topo das células (15 Km a jusante de Camaruã, rio Purus, AM, Brasil, ninho 360c); 42, favos normais, sem rebaixo (Camanaus, AM, Brasil, ninho 210c); 43, favo com o cerume removido, pelas abelhas, na parte central, expondo os casulos (Alter do Chão, PA, Brasil, ninho 170c); 44, massa de pólen removida de um pote, recoberta por leveduras Candida sp. - cada bolota corresponde a uma carga de pólen depositada pelas abelhas (Cachoeira da Porteira, PA, Brasil, ninho 180c); 45, potes de pólen - alguns abertos mostrando as colônias de leveduras (Curicuriari, rio Negro, AM, Brasil, ninho 217c). Figs. 40-42 na mesma escala. Escalas $=10,0$ mm. 
12 favos, encimados por favos novos, com células em construção, que, sucessivamente, vão preenchendo os espaços deixados pelos favos velhos, com cria nascente (Fig. 33). Há, usualmente, entre 100 a 300 células em construção. O número de favos, em ninhos já bem maduros, varia entre $30 \mathrm{a}$ 60; os maiores, com 10-12 cm de diâmetro, comportam ca. de 500-600 células. Não considerando os favos novos, com células em construção, que representam ca. de $20 \%$ do total, pode-se estimar entre 15.000 a 30.000 células por ninho e, por inferência, uma população adulta com aproximadamente o mesmo montante.

Os favos são sustentados por grossos pilares de cerume, que são gradualmente removidos, à medida que o favo cresce, ficando somente aqueles da periferia. Os casulos, ou células com cria nascente, medem, internamente, $4,17 \mathrm{~mm}$ de diâmetro por $7,2 \mathrm{~mm}$ de altura. As realeiras, que são encontradas às vezes em grande número (em um dos ninhos foram contadas 20 delas) na periferia dos favos ou fixadas, isoladamente, no invólucro, medem, internamente, ca. de 8,5 x 12,0 mm.

Uma das peculiaridades de alguns ninhos de $P$. lurida diz respeito à forma de construção das células. As células novas são construídas com ca. de 9-11 mm de altura. Depois de receberem o aprovisionamento e a oviposição, são operculadas com um tampão de cera, o qual, em seguida, sofre um gradual rebaixamento na parte central, de modo que as bordas das células ficam salientes, formando, no topo destas, alvéolos com 1-3 mm de profundidade. Em seguida, muito cerume é acrescentado às partes salientes, dando ao favo um aspecto muito peculiar, conforme indicado nas Figs. 40, 41, 43. Esse processo de rebaixamento do topo das células não ocorre em todos os ninhos; em uma mesma localidade pode-se encontrar ninhos com favos com ou sem rebaixamento (Fig. 42), como observado na região do alto rio Negro (Camanaus e Curicuriari). São as seguintes as localidades onde foram encontrados ninhos com favos com o topo das células rebaixado, formando alvéolos: Alter do Chão, PA (ninho 170c), Cachoeira da Porteira, PA (180c), Igarapé Maripá, Urucará, AM (205c) Curicuriari, alto rio Negro, AM (217c), Samaúma, rio Demini, AM (811c) e Camaruã, rio Purus, AM (360c); localidades onde foram encontrados ninhos com células sem rebaixamento na parte superior: Camanaus, alto rio Negro, $\mathrm{AM}$ (210c e 727c), Caracaraí, RR (272c), Maraã, AM (600c) e São Jorge, alto rio Negro, AM (=Curicuriari, $722 \mathrm{c})$.

Quando as crias iniciam a confecção do casulo, a cera e o cerume que constituem o opérculo e o fundo das células, vão sendo gradualmente removidos pelas operárias, conforme indicado na Fig. 43.

As células são preenchidas com alimento semi-líquido até um pouco acima do meio. Em material fixado (Dietrich) e conservado em álcool $70 \%$, pôde-se identificar pólen em grande quantidade, misturados a uma massa amorfa, como geléia. É possível que parte desse alimento seja constituído de leveduras que se desenvolvem no pólen estocado nos potes. É, também, provável que ocorra fermentação dentro das células, visto que há, sempre, muitas bolhas de gás no interior da massa alimentar. Esse processo de fermentação poderia explicar o rebaixamento do topo das células, como descrito acima.

Os potes de pólen, muito numerosos (300-400, ou mais), usualmente estão distribuídos embaixo e ao redor da região de crias, entre os invólucros externo e interno (Fig. 33); são construídos de cerume marrom-castanho ou avermelhado, com as paredes geminadas, muito finas $(0,2-0,3 \mathrm{~mm})$, formando uma única grande massa (Figs. 33, 45); medem ca. de 1,5 a 3,5 cm de altura por 1,2 a 2,0 cm de diâmetro. O pólen é estocado em grande quantidade; em um dos ninhos (ninho 363c, Arimã, rio Purus, AM), havia ca. de 3,0 kg.

Como já relatado por CAMARGO et al. (1992), o pólen é estocado em associação com leveduras - Candida sp., que promovem sua dessecação e longevidade na ensilagem (Figs. 44, 45). A ação das leveduras torna o pólen armazenado tão seco, que chega a produzir enrugamento e deformação das paredes dos potes (Fig. 45). As cargas de pólen depositadas pelas abelhas não se dissociam, ficam perfeitamente individualizadas (Fig. 44) e se esfarelam ao menor toque. É possível que a impermeabilização das paredes do oco e as grossas lamelas de resina envolvendo todo o ninho, tenham relação com o processo de dessecação promovido pelas leveduras (ver, mais adiante, comentários sobre resinas florais de Clusia spp.).

Potes com "mel", ou líquidos adocicados, são relativamente raros ou mesmo totalmente ausentes em alguns ninhos. Em apenas três dos ninhos, abertos para estudo, havia alguns potes ( 4 potes em um deles e ca. 10 ou pouco mais nos outros) contendo "mel" de bom sabor, de cor âmbar e bem desidratado. Geralmente, o que se encontra, são potes com uma substância aquosa ácida, às vezes com grumos esbranquiçados misturados (DUCKE 1916b: 70, também se refere a mel "azedo, enjoativo"). Dosagens feitas com amostras dessa substância, obtidas de ninhos da região de Manaus, AM, indicam um baixo teor de açúcares totais, entre 7\% e 14\% (Kaminski, com. pessoal).

Os potes com mel ou com a substância aquosa são encontrados, agrupados, anexos aos potes de pólen ou na parte inferior do ninho, entre as lamelas do batume (Fig. 33); são um pouco maiores $(3,0-3,5 \mathrm{~cm}$ de altura, por $2,0-2,5 \mathrm{~cm}$ de diâmetro) que os de pólen e com a parte superior estreitada, lembrando, vagamente, a forma de moringa ou porongo; as paredes são de cerume marrom-escuro e um pouco mais grossas.

Intercalados com os potes de pólen ou, principalmente, na parte inferior do ninho, entre as lamelas de batume, existem, geralmente, muitos potes contendo uma substância pastosa, viscosa, não solúvel em água, de cor marrom-amarelada que, no início, suspeitou-se tratar de resinas florais de Clusia spp., visto que $P$. lurida é um visitante assíduo dessas flores (Mesquita \& Franciscon 1995; Camargo \& Pedro, várias observações pessoais, e Kaminski, com. pessoal). Uma análise microscópica de algumas amostras dessa substância confirmou a supeita; em uma delas havia grande quantidade de grãos de pólen de Clusiaceae [Clusia panapanari (Aubl.) Choisy] misturados. Adicionalmente, também, foi encontrado pólen de Burseraceae [Protium heptaphyllum (Aubl.) 


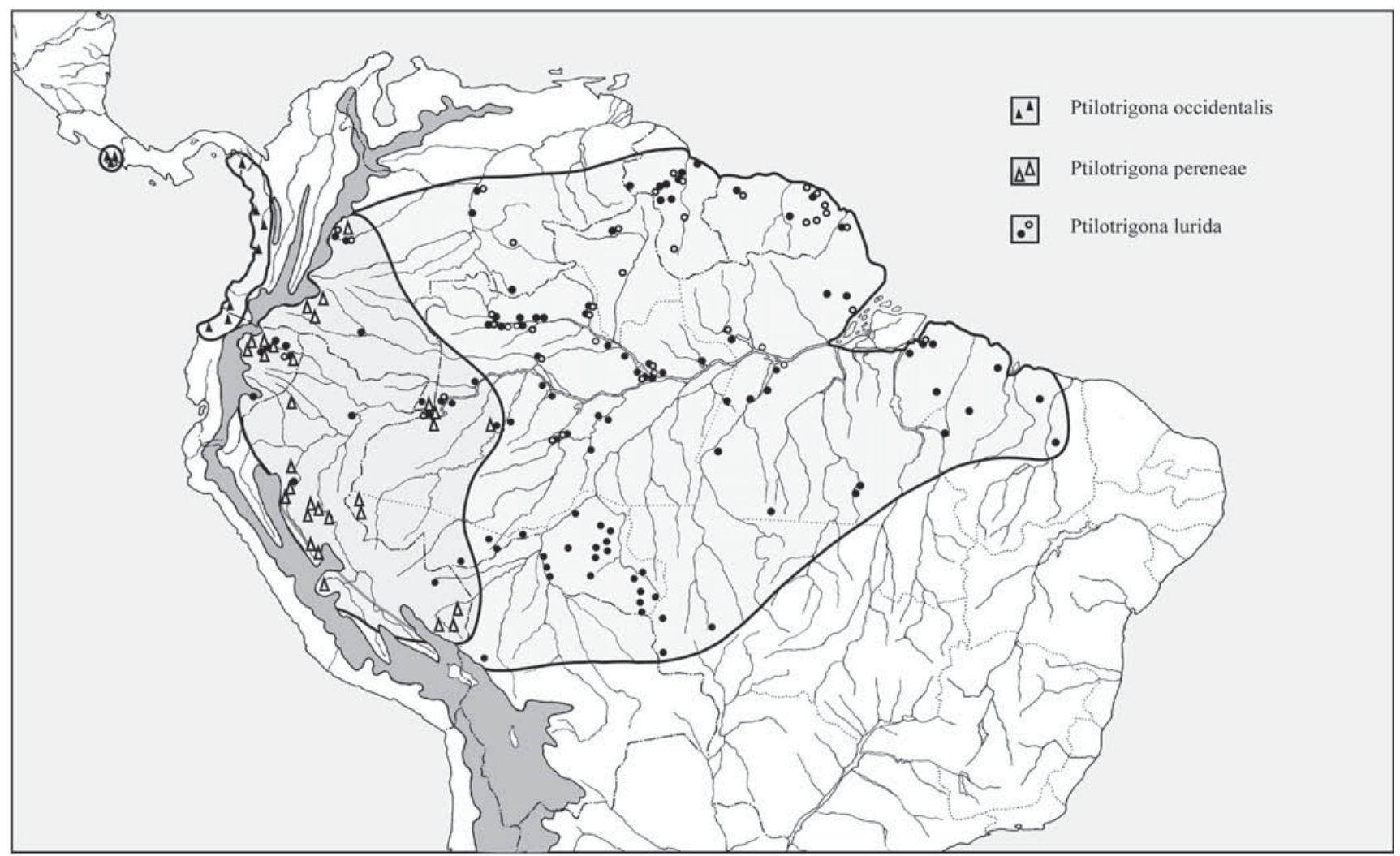

Fig. 46. Ptilotrigona, distribuição geográfica das espécies. Em P. lurida, os círculos cheios indicam exemplares com o terço apical da tíbia e basitarso III pretos; círculos vazados, exemplares com a perna III toda amarela.

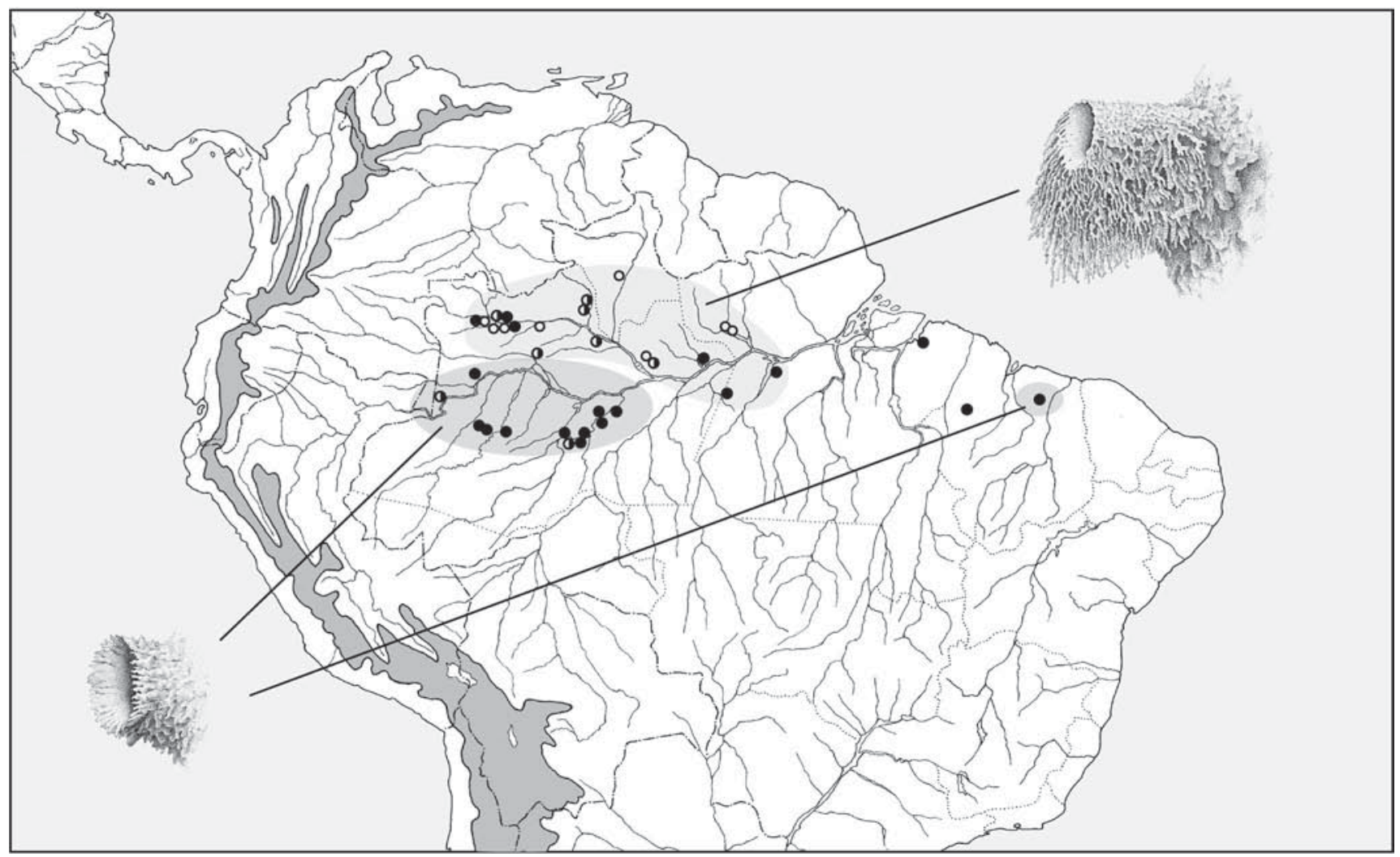

Fig. 47. Ptilotrigona lurida, localização dos ninhos estudados, indicando a variação na forma do tubo de entrada e padrão de cores da perna III os círculos cheios indicam ninhos com exemplares com o terço apical da tíbia e basitarso III pretos; círculos vazados, exemplares com a perna III toda amarela; círculos metade vazados, desde exemplares com pernas amarelas, variegadas, até pretas. 
Marchand] (Kaminski, com. pessoal). Os potes contendo essas resinas têm as paredes constituídas de cerume ou de resinas enegrecidas e muito endurecidas, e são iguais, em tamanho, àqueles de mel.

Não se sabe exatamente qual a destinação dessas resinas. Uma das funções talvez esteja na defesa do ninho (as abelhas têm o hábito de colocar resinas sobre os invasores), mas, o mais provável é que sejam utilizadas como material estrutural, misturadas com a cera, constituindo o cerume que é utilizado na construção de células, potes e lamelas do invólucro de crias. Uma evidência desse uso está no fato de que, em amostras de cerume, retiradas do topo das células de cria (ninho 170c), e dissolvidas em benzina, foram constatados muitos grãos de pólen de Clusia misturados, idênticos àqueles de Clusia panapanari encontrados nos potes. Em adição a essa função mecânica, pode-se suspeitar, também, de uma função antimicrobiana. LOKVAM \& BRADDOCK (1999) desenvolveram alguns ensaios microbiológicos para testar a atividade das resinas florais de Clusia grandiflora Splitg., e encontraram que estas têm atividade bactericida contra várias cepas de bactérias Gram-positivas e Gram-negativas, obtidas do corpo de operárias de Paratrigona anduzei (Schwarz, 1943), mas nenhuma atividade contra três diferentes tipos de leveduras e alguns fungos filamentosos. Isso é particularmente interessante, visto que $P$. lurida estoca pólen em associação com leveduras, como descrito acima. Nesse caso, é plausível supor que a ação das resinas de Clusia pode promover o crescimento das leveduras sobre o pólen, livre da contaminação por bactérias. Isso, também, poderia explicar a grande quantidade de resinas de Clusia estocada dentro de potes, um modo de estocagem único entre os Meliponini. As outras espécies conhecidas de Meliponini estocam resinas, de vários tipos, fixadas nas paredes do oco, entre as lamelas de invólucro, etc., mas não em potes.

Comportamento de defesa. Ptilotrigona lurida está entre os Meliponini mais "agressivos" conhecidos na região neotropical. Muitas abelhas ficam no tubo de entrada e atacam à menor aproximação; às vezes reagem à presença do observador a $10 \mathrm{~m}$ ou mais de distância do ninho, e o atacam e perseguem por dezenas de metros. Centenas de indivíduos, ou mesmo mais de um milhar, saem do ninho muito rapidamente e atacam mordendo as partes expostas do corpo e se enrolando no cabelo e cortando-o; freqüentemente, também, depositam resinas (DUCKE 1916b: 70). Em certa ocasião, um dos autores (JMFC) abandonou a câmara fotográfica, sobre o tripé, próxima a um ninho, e as abelhas recobriram-na, quase totalmente, com resinas.

Flores visitadas para coleta de pólen. Em amostras de pólen obtidas dos potes em ninhos de P. lurida nas regiões do baixo Tapajós, PA, Trombetas, PA, e Uatumã, AM, foram encontradas as seguintes espécies florais: Aptandra liriosmoides Spruce ex Miers (Olacaceae), Bactris gasipaes H. B. \& K. ( Palmae), Byrsonima sp. (Malpighiaceae), Cecropia sp. (Moraceae), Clusia columnaris Engl. (Guttiferae), Cordia sp.
(Boraginaceae), Crudia amazonica Spruce, e Cynometra sp. (Leg. Caesalpinioidea), Davilla sp. (Dilleniaceae), Inga sp. (Leg. Mimosoidea), Mabea nitida Spruce ex Benth e Mabea sp. (Euphorbiaceae), Maximiliana martiana Karst. (Palmae), Mora paraensis Ducke (Moraceae), Stryphnodendron guianense Ducke (Leg. Mimosoideae) e Tapirira guianenis Aubl. (Anacardiaceae), além de várias outras espécies não identificadas de Lecythidaceae, Moraceae, Myrtaceae, Palmae e Sapotaceae (ABsy et al. 1984); na região de Manaus, Mimosa invisa Mart. e Mimosa sp. (Leg. Mimosoideae), Clusia insignis Mart. (Clusiaceae), Protium heptaphyllum March (Burseraceae), Didymopanax morototoni Decne \& Planch. (Araliaceae), Stryphnodendron sp. (Leg. Mimosoideae), Myrtaceae, Melastomataceae e Anacardiaceae (Kaminski, com. pessoal, pólen obtido de células de crias). DUCKE (1902b: 305) relata visitas de $P$. lurida em flores de Dichromena ciliata Vahl (Cyperaceae) e também em Hevea sp. (Euphorbiaceae) coletando látex. FALCÃo et al. (2000) registram P. lurida como um visitante freqüente em flores de "Araçá-boi", Eugenia stiptata McVaugh (Myrtaceae), na região de Manaus. Nas etiquetas de alguns dos espécimens estudados (item "Material examinado") constam: Leopoldinia piassaba Wallace e Astrocaryum vulgare Mart (Palmae).

Discussão. A lista de sinônimos aqui apresentada foi, inicialmente, sugerida por ScHWARZ (1938: 468), embora esse autor tenha conservado T. (Tetragona) heideri heideri como nome válido para a espécie, porque tinha dúvidas quanto à identidade de T. testacea e T. lurida. Essa possível sinonímia foi confirmada por Moure (1963: 263), na ocasião em que estudou o tipo de Trigona testacea Spinola, 1853 (non Klug, 1807), e também propôs a inclusão de Trigona mocsaryi como sinônimo júnior. Moure chama a atenção para o fato de que as séries-tipo tanto de T. mocsaryi como de T. heideri incluem exemplares do Pará (= Belém?), coincidindo, assim, com a localidade-tipo de T. testacea (=P. lurida). A série-tipo de $T$. heideri inclui exemplares do "Pará" ("Ducke, 29 Septbr., 11 Novbr. 1899"), Óbidos, PA, S. Paulo [de Olivença] e Fonte Boa, AM, Vilcanota, Peru, e Colômbia; a de T. mocsaryi, exemplares do "Pará" e Suriname. Esses tipos não foram vistos, todavia foram examinados vários exemplares do "Pará", identificados por Friese, em data posterior, inclusive três deles com etiquetas de "TYPUS" (item "Material examinado"; havia além destes, inclusive um exemplar de Camargoia camargoi de "Brasil, Pará, 6.1904, Ducke, acc. 22899" (AMNH), com etiqueta de "TYPUS", "T. heideri, 909 Friese det."). O tipo de Trigona manni Cockerell, 1912 ( $\mathrm{N}^{\circ}$ 23526, USNM) de Porto Velho, RO, foi reexaminado, aliás, o próprio CoCKERELL (1920: 463) já havia reconhecido a identidade desta com T. heideri (= P. lurida). Trigona mocsaryi lutea foi descrita com base em exemplares de Óbidos e do "Pará (Amazonas)" coletados por Ducke; FRIESE (1903) refere-se ao disco do tórax amarelado para distinguí-la de T. mocsaryi. Esses tipos não foram vistos; supõe-se que se tratam de exemplares jovens de $P$. lurida.

A forma com as tíbias e basitarsos III inteiramente amarelos, descrita por Friese como T. mocsaryi, predomina na região ao 


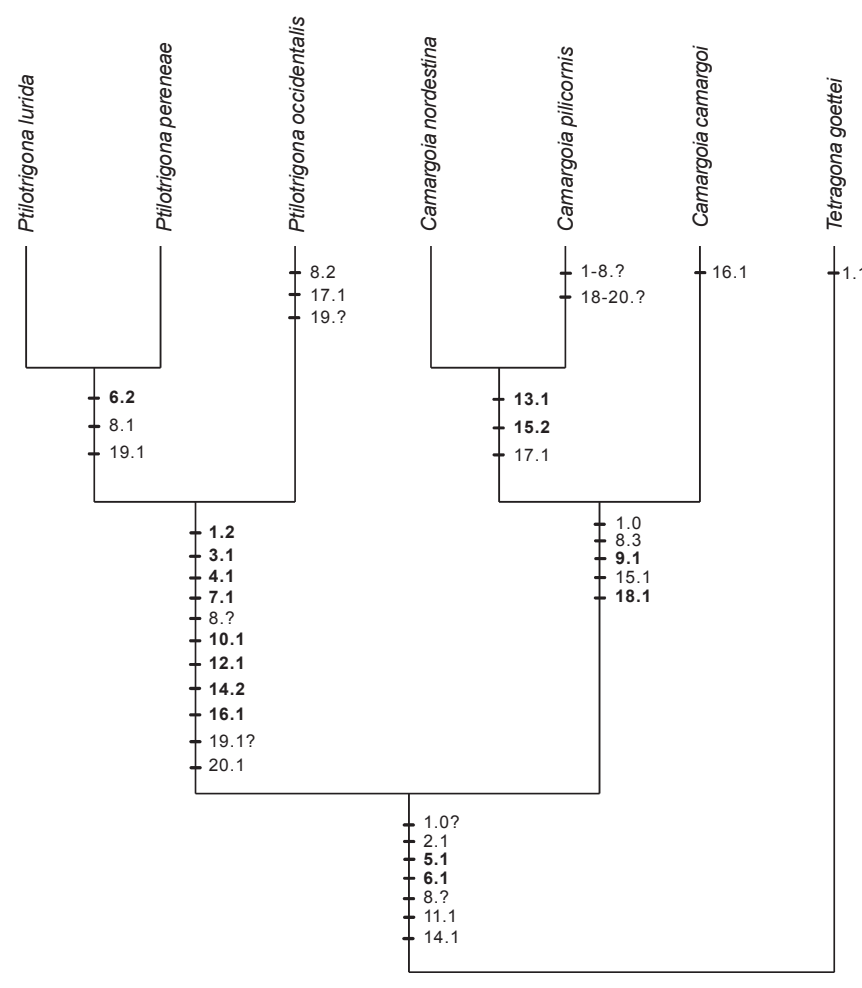

Fig. 48. Hipótese de filogenia para as espécies de Ptilotrigona e gêneros relacionados. Números em negrito indicam sinapomorfias.

norte dos rios Negro e Amazonas até as Guianas e Surinamesendo, aí, raros os indivíduos com pernas pretas - , e ao sul desse alinhamento, predomina a forma com o terço apical das tíbias III e respectivos basitarsos, pretos (atributos que correspondem aos do tipo de P. lurida). Havia, assim, a suspeita de que o táxon fosse composto, senão de duas espécies, ao menos de populações ou "raças" geográficas mutuamente exclusivas. O exame de longas séries de indivíduos obtidos em 38 ninhos em diferentes localidades da Amazônia (Fig. 47), embora permita excluir a hipótese de espécies distintas, não revela esse caráter como um indicador inequívoco de padrões geográficos. $\mathrm{Na}$ área de contato entre essas duas "formas" - ao longo do alinhamento dos rios Amazonas e Negro -, não só ocorrem ninhos das duas "formas puras", mas também ninhos onde os indivíduos apresentam intergradação, desde aqueles com o terço apical da tíbia e basitarso III pretos, até indivíduos com estas partes mescladas ou inteiramente amarelas (p. ex.: espécimens dos ninhos $726 \mathrm{c}$ de Camanaus, 810c de Pai Raimundo e 811c de Samaúma, estas duas últimas localidades na região do baixo rio Demini, $820 \mathrm{c}$ de Tapera, lago Caurés e 654c de Manaus, $70 \mathrm{Km} \mathrm{N}$; ver item "Material examinado" e Fig. 47). Esse padrão de intergradação, sem dúvida, poderia ser indicativo de zona de hibridação. Todavia, essa mesma variação na cor da perna posterior, volta a ocorrer na região de Letícia, alto Solimões (ninho 62c, Vendaval), em Yasuni, Equador, e nas regiões do médio Juruá - Purus ( ninho 372c, Arimã) e baixo Japurá (ninho 600c, Maraã), de modo que, esse caráter, acaba "perdendo" seu significado como indicador de padrão geográfico. Nesse sentido, a decisão de Moure (1963) de considerar T. mocsaryi como sinônimo de P. lurida parece acertada. Também não há, com relação à morfologia, pilosidade, etc., tanto das operárias como dos machos (nestes, a genitália e esternos pré-genitais são idênticos), qualquer caráter, ou descontinuidade, correlacionado com a cor das pernas, indicativo de táxons distintos, ou de outros eventuais padrões geográficos. Há, por outro lado, variação com relação ao comportamento. As entradas dos ninhos estudados na região do alto Solimões e médio e baixo rios Juruá e Purus, e na região de Chapadinha, MA, conforme comentado no item "Estrutura de entrada", apresentam pouca ornamentação (Figs. 38, 47), enquanto nas demais áreas desde o baixo Tapajós até o alto rio Negro, as entradas são ornamentadas com um emaranhado de longas estruturas radiculiformes (Figs. 35, 39, 47). Essa variação, embora possa ser indicativa de uma história de diferenciação geográfica, não está correlacionada com nenhum caráter morfológico ou de cores, e não há como operacionalizá-la em termos taxonômicos. Em vista dessa impossibilidade, dentro dos limites da análise aqui conduzida, optou-se por considerar essas variantes todas, apenas sob a designação de $P$. lurida.

Com relação ao tamanho dos indivíduos, também há uma notável variação, mas sem regularidade geográfica e, às vezes, dentro de um mesmo ninho. Em uma série de operárias obtidas na localidade de Vendaval, alto Solimões, AM (ninho s/n, 1618.I.1977, Camargo - M. Mazucato), a largura da cabeça varia entre 2,37 até $2,8 \mathrm{~mm}$; em amostras coletadas em "B.A.B.A." $($ sic $=$ Bê-a-bá), rio Purus, AM (ninho 380c) e em Vila Nova, rio Andirá, PA (ninho 869c), a largura da cabeça varia entre 2,6 e $2,8 \mathrm{~mm}$. Os indivíduos maiores foram encontrados na região do Igarapé Maripá, rio Uatumã, AM (ninho 205c), com a largura da cabeça entre 2,82 e 2,85 $\mathrm{mm}$.

Para um reconhecimento mais acurado de $P$. lurida em relação às demais espécies do gênero, ver discussão e comentários em $P$. pereneae e $P$. occidentalis.

\section{Ptilotrigona pereneae (Schwarz, 1943)}

Trigona (Tetragona) heideri pereneae Schwarz, 1943: 3.

Melipona heideri; Ducke, 1916b: 69; 1925: 383 (partim, formas com as pernas escuras da Amazônia ocidental).

Trigona heideri pereneae; Moure, 1944: 72.

Trigona (Ptilotrigona) lurida pereneae; Moure, 1963: 264.

Ptilotrigona pereneae; Coloma, 1986: 24, 103, 132, 133, 135; Silveira et al., 2002: 91, 249.

Ptilotrigona lurida pereneae; Camargo, 1988: 359; Camargo et al., 1992: 391 .

Diagnose. Operária. Largura da cabeça entre ca. de 2,703,06 mm; comprimento da asa anterior, desde o ápice do esclerito Costal, entre 8,80-9,55 mm. Integumento desde predominantemente amarelado, mesclado de amarelo e castanho-escuro, até bem enegrecido, exceto pelos desenhos amarelos na face e faixas nos lados do mesoscuto e axilas; clípeo com mancha preta a cada lado e larga faixa apical 
(igualando a metade do diâmetro do escapo, Fig. 29); mesoscuto preto; escutelo geralmente preto; mesepisternos geralmente enegrecidos, apenas com faixa amarela no meio; nos indivíduos mais escurecidos, o enegrecimento atinge os pares de pernas II e III, apenas com manchas mais claras na base da tíbia III e trocanteres; nos indivíduos mais claros, a tíbia e o basitarso da perna III são por inteiro amarelados ou castanhos; membrana das asas anteriores tingida de amareloferrugíneo, como em P. lurida, e microtríquias enegrecidas no ápice da asa (como em $P$. lurida), ou chegando até próximo da base desta. Macho. Cor do integumento como nas operárias; cerdas do esterno VI como em P. lurida; parte distal dos ganchos da valva, ca. de 3,2 vezes mais longos que o bulbo basal; gonóstilos levemente dilatados e arredondados no ápice (Fig. 18, como em P. lurida).

\section{Macho. Figs. 16, 18, 32.}

Material-tipo. Holótipo, operária, e vários parátipos de "El Campamiento, Colony Perené, Peru", depositados na Cornell University Insect Collection (CUIC); outros parátipos da mesma localidade no AMNH, e um na RPSP com as seguintes etiquetas: "PARATYPE" (em vermelho), "Hda. San Juan, Col. Perené, PERU, June, 1920", "Cornell Univ. Expedition, Lot. 569", e etiq. manuscrita de Schwarz, "Trigona heideri pereneae Schwarz".

Material examinado. COLÔMBIA. Caquetá: Caquetá [sem localidade], 10.IV.1978, César Garcia (2 ops., DZUP); ibidem, idem, cerca al Paujil, 450m, 10.IV.1978 (2 ops., DZUP); La Mona, 20 (19).V.1981, G. Parra (3 ops., STRI; 1 op., RPSP); La Rastra Wald, Vorm. 22.IV.1956, Stuorn (1 op., DZUP). Cundinamarca: Medina, 732'2" W, 430’20" N, 20-24.IX.1977, G. N. Parra (10 ops., RPSP). Amazonas: Letícia, VII.1967, M. Tye (1 op., CASC); ibidem, 65 Km W, Amacayacu Nat. Park, 17-30.IX.1986, D. Roubik (1 op., STRI; 2 ops., RPSP); P.N.N. Amacayacu, VIII.1990, F. Fernandez (1 macho, STRI). EQUADOR. Sucumbios: Cuyabena, Napo-Pastaza, 26.V.1958, R. W. Hodges (2 ops., MSUC); Limoncocha, Oriente, 00²4'S, 76³6'W, 29.VII.1970, M.G. Naumann, 109 (26 ops., SEMC; 3 ops., RPSP); Sacha Lodge, $0.5^{\circ} \mathrm{S}, 76.5^{\circ} \mathrm{W}, 270 \mathrm{~m}, 3 . \mathrm{IV}-4 . \mathrm{V} .1994$, Hibbs, ex: malaise (1 macho, RPSP); ibidem, idem, 4-14.III.1994 (2 ops., SEMC); ibidem, idem, 24.III-3.VI.1994 (1 op., SEMC); ibidem, idem, 3-13.IV.1994 (1 macho, SEMC); ibidem, idem, 23.VI-3.VII.1994 (1 macho, SEMC); ibidem, idem, 27.VIII-10.XI.1994 (1 op., SEMC); ibidem, idem, 13-25.VII.1994 (1 op., 1 macho, SEMC); ibidem, idem, 3-16.VIII.1994 (1 op., LACM; 1 macho, SEMC); ibidem, idem, 1222.II.1994, malaise trap (2 machos, LACM); ibidem, idem, 22.II4.III.1994 (1 macho, LACM); ibidem, idem, VII.1994 (1 op., LACM). Napo: Coca [= Puerto Francisco Orellana?], XI.1984, G. Onore (1 op., SEMC; 3 ops., RPSP); SC Yasuni, V.1997, P. Ponce (2 ops., 00024142, RPSP); ibidem, sem data, anônimo (2 ops., STRI; 1 op., RPSP); ibidem, Yasuni Nat. Park, Est. La Catolica, 14-26.IV.1998, D. Roubik (4 ops. STRI; 3 ops., RPSP); ibidem, idem, 13-27.IV.1998 (2 ops., STRI); ibidem, idem, 7-15.XI.1998 (2 ops., STRI); Reventadora [sic] area, near San Rafael Falls, 1500 m, 6.I.1989, K. R. Hobson \& E. A. Bergery, "general collecting" (4 ops., EMEC); Pastaza: Puyo, 20.VIII.1986, G. Onore (2 ops., RPSP). PERU. Loreto: Huallaga, VII.1961, F. H. Walz (7 ops., DZUP); ibidem, idem, XI.1961 (13 ops., DZUP); Teniente Lopez, $1.5 \mathrm{Km} \mathrm{N}, 2^{\circ} 35.66^{\prime} \mathrm{S}, 7^{\circ} 06.92^{\prime} \mathrm{W}$, 23.VII.1993, 210-240m, R. Leschen, 191 ex: flight intercept trap (1 op., SEMC). San Martín: Bosque Quinllal [sic = Quinillal], near Picota, 8.IV.2002, C. Rasmussen (1 op., MUSM); TarapotoYurimaguas [road], Km 30, Caserio Progreso, [South]0827 / [West]7619, 550 masl, VI.2002, C. Rasmussen (2 ops., MUSM; 1 op., RPSP). Huánuco: Tingo Maria, 22.VI.1962, W. T. Van Velzen (7 ops., MSUC). Ucayali: Neshuya, Loreto, 240m, 25-28.XI.1964, J.
Schunke (1 op., LACM); Previsto, 800-899m, 6.V.1965, J. Schunke (1 op., LACM); Pto. Boquerón Abad [= Boquerón del Padre Abad], 22.XII.1962, J.M. Schunke (9 ops., DZUP); ibidem, idem (apenas Boquerón na etiq.), 500 m, 7-14.VII.1965 (19 ops., LACM); Pucallpa, 17.VII.1959, J. Schunke (5 ops., DZUP); ibidem, idem, XII.1962 (12 ops., DZUP); ibidem, idem, 19.I.1963 (4 ops., DZUP); ibidem, idem, 4.VI.1963 (3 ops., DZUP); ibidem, idem, 200m, 1-10.X.1964 (25 ops., LACM); ibidem, idem, 1-10.XI.1964 (7 ops., LACM; 3 ops., USNM); ibidem, idem, 20-30.VI.1965 (1 op., LACM); ibidem, 5.VIII.1962, W. T. Van Velzen (4 ops., MSUC). Pasco: Chontilla, 22 Km SE Iscozazin, 20.VII.1961, F. S. Truxal (1 op., LACM; 1 op., DZUP); Iscozazin [sic = Iscozacín], 18-19.VII.1961, F. S. Truxal (1 op., LACM); Pan de Azucar, 13.VII.1961, F. S. Truxal (4 ops., LACM); ibidem, idem, 25.VII.1961 (1 op., LACM). Junin: V. Chanchamayo, 13.XI.1961, J. M. Schunke, "Ptilotrigona pereneae (Schw.), Pe. J. S. Moure 1984" (1 op., DZUP). Cuzco: Avispas, 20.IX.1963, Luis E. Peña (12 ops., DZUP); Hacienda Maria, 28.II.1952, F. Woitkowski (2 ops., SEMC); Pilcopata, 2.XI.1963, anônimo, "vuelo" (1 op., LACM); ibidem, 18.II.1993, L. Gonzalez (2 ops., UNALM; 1 op., RPSP). Madre de Dios: Tambopata Jungle Lodge, 225 m.a.s.1., S12 49,456 W69 24,163, 20.X.2001, C. Rasmussen, CR-547 (3 ops., MUSM; 2 ops., RPSP). Departamento?: Peru [sem localidade especificada], 1900, anônimo, acc. 22899, etiq. salmão: "TYPUS", etiqueta de Friese: "Trigona heideri, 1910, Friese, det. Fr." (1 op., $\mathrm{AMNH}$ ) [não pertence à série-tipo original]; ibidem, idem, "Trigona heideri, Friese det. '25, Fr." (1 op., AMNH); Yurec [prov. Yurac, Huánuco, ca. 107 km L de Tingo Maria], 300 m, 30.VII.1948, E. Vialle C. (1 op., MSUC). BRASIL. Acre: Parque Nacional Serra do Divisor, 7340’28" W, 7²6’36" S (Morro Queimado, sítio 1, Trilha do Anil, sítio 6) 8-9 e 10.XI.1996, E. F. Morato (8 ops., 971028-031, 971034, 971499, 971501-502, RPSP); ibidem, idem, Rio das Minas, sítio 6, 7253'30"W, 8³3'30"S, 19.III.1997 (1 op., 972460, RPSP). Amazonas: Tabatinga, VII.1957, E. S. Lima (4 ops., DZUP); Benjamin Constant, SB-19, 70-4c, 13-14.I.1977, Camargo, Mazucato (1 op., AMNH; 1 op., SEMC; 8 ops., RPSP); Carauari, rio Juruá, 66 $54^{\prime} \mathrm{W}, 4^{\circ} 53^{\prime}$ 'S, 20-24.VII.1993, Camargo, Pedro, Mazucato (44 ops., 1 macho, mais exemplares em fixador, ninho 517c, RPSP).

Distribuição geográfica. Matas do oeste da Amazônia Colômbia, Equador, Peru e Brasil (Fig. 46). Provavelmente ocorre também no norte da Bolívia (SchwARz 1943: 4).

Nidificação - substrato e hábitat. Vive em matas úmidas e, de acordo com C. Rasmussen (que forneceu fotos e informações, in litteris, de um ninho encontrado na região de Tarapoto, Peru), nidifica em ocos de árvores vivas e a entrada é constituída de um tubo muito estreito, com ca. de $1 \mathrm{~cm}$ de largura por $6-8 \mathrm{~cm}$ de altura, e relativamente curto, $3-4 \mathrm{~cm}$ de comprimento; construído com resinas, muito endurecidas, e liso, sem ornamentos radiculiformes, apenas o bordo distal um pouco revirado e levemente crenulado. Essa estrutura de entrada é exatamente igual à de um ninho estudado na região do médio rio Juruá (517c, Carauari, AM), apenas neste era um pouco mais longa ( $10 \mathrm{~cm}$ de comprimento, e a boca mais alta $\mathrm{e}$ mais estreita, $8 \mathrm{~cm}$ de altura por $0,6 \mathrm{~cm}$ de largura), com as bordas reviradas, em forma de lábio, e levemente crenuladas (Figs. 36, 37). Nas estruturas internas este ninho em nada diferia daquele de P. lurida, somente as células de cria não apresentavam rebaixo na parte superior, o que também ocorre em alguns ninhos desta última (ver dados bionômicos de $P$. lurida). Havia, também, levedura associada ao pólen estocado. As abelhas deste ninho, entretanto, são amarelas e indistiguíveis de P. lurida (ver "Discussão"). 
Comportamento de defesa. Como em P. lurida (observações referentes ao ninho 517c, e ninho de Tarapoto, Peru, C. Rasmussen, in litt.).

Discussão. Interpretou-se $P$. pereneae com base na descrição original de Schwarz (1943) e no estudo de um dos parátipos. Havia a suposição de que $P$. pereneae pudesse ser apenas uma forma melânica de $P$. lurida, a exemplo do que ocorre com outras espécies de Meliponini no extremo oeste da Amazônia [por exemplo: forma melânica de Partamona testacea (Klug, 1807) (Pedro \& CAMARgo 2003: 57-58)]. Todavia, esses dois "táxons" ocorrem em simpatria em uma larga extensão (Fig. 46) e, especialmente na região de Sacha Lodge, Limoncocha (Sucumbios) e Yasuni (Napo), no Equador, onde foram coletados lado a lado, pôde-se notar certas descontinuidades não só com relação à coloração dos exemplares, mas também ao tamanho - sem intermediários, o que constitui indício de que $P$. pereneae seja, de fato, uma espécie distinta, e não meramente uma variante melânica, ou que essa variação possa ocorrer dentro da população de um mesmo ninho. Nessas localidades, os exemplares de $P$. pereneae são maiores (largura da cabeça entre 2,85 e 3,00 mm) e apresentam forte melanismo; no clípeo, as duas manchas laterais e a larga faixa (tão larga como metade do diâmetro do flagelo) ao longo de toda a margem apical são fortemente enegrecidas, e também todo o corpo, inclusive o escutelo. Os exemplares interpretados como $P$. lurida, dessas mesmas localidades, têm a largura da cabeça entre 2,55 e 2,70 mm, aproximadamente; o clípeo é praticamente por inteiro amarelo - as manchas laterais são muito difusas e apagadas e a faixa distal muito estreita e reduzida a porção mediana; o corpo é bem amarelado, apenas com enegrecimento no terço distal da tíbia III e respectivo basitarso (além das partes usualmente pretas, como mesoscuto e cabeça).

Em algumas localidades, entretanto, os exemplares são bem amarelados e indistinguíveis de $P$. lurida. Esse é o caso, por exemplo, dos espécimens obtidos do ninho 517c (de Carauari, AM, Brasil), atribuído a $P$. pereneae, com base apenas nos caracteres comportamentais: tubo de entrada liso, muito estreito e alto (Figs. 36, 37), e idêntico àquele do ninho visto em Tarapoto, Peru, conforme descrito anteriormente, cujos exemplares colecionados são bem enegrecidos. Supõe-se que esse formato de entrada constitua um padrão, já que foi encontrado em duas localidades muito distantes (convém salientar que em Tarapoto também foi encontrado um ninho de $P$. lurida, e de acordo com foto enviada por C. Rasmussen, a entrada deste era muito semelhante àquelas encontradas na região do alto Solimões e baixo Juruá, Fig. 38), e que possa constituir um critério para o reconhecimento de $P$. pereneae. Em $P$. lurida, o tubo é aproximadamente cilíndrico ornamentado com estruturas radiculiformes (ver descrição e Figs. 35, 38, 39). Para exemplares de corpo bem amarelo, dessa região, colecionados fora dos ninhos, contudo, não há como reconhecê-los; não há caracteres qualitativos discretos além da coloração (é possível que alguns exemplares estejam identificados erroneamente nas coleções). Apenas alguns exemplares, às vezes, podem ser reconhecidos pela coloração do clípeo - as manchas a cada lado e a faixa distal, bem enegrecidas -, e pelas pernas posteriores variegadas, sem manchas distintas. Quanto aos machos, só uns poucos exemplares melânicos foram examinados, mas com relação à morfologia são idênticos aos de $P$. lurida, inclusive nos atributos da genitália e esternos pré-genitais, apenas o gancho da valva é um pouco mais curto (Fig. 18).

Diante do exposto, e na ausência de outros tipos de evidências que possam ser contrárias, considera-se $P$. perenae como espécie distinta, apesar das dificuldades em reconhecêla sem informações sobre a forma da entrada do ninho.

\section{Ptilotrigona occidentalis (Schulz, 1904)}

Trigona Heideri [sic] occidentalis Schulz, 1904: 821; Marianno, 1911: 103; Cockerell, 1920: 463.

? Trigona heideri Friese, 1900: 26 (exemplares da Colômbia, de acordo com Moure, 1963: 263)

Melipona heideri, forma occidentalis; Ducke, 1916b: 68.

Melipona heideri, var. occidentalis; Ducke, 1916b: 70; 1925: 383.

Trigona suffragata Cockerell, 1922: 9; Moure, 1963: 263 (syn.).

Trigona (Tetragona) heideri occidentalis; Schwarz, 1943: 4; Parra, 1984: 284; 1990: 82, 92, 95, 98.

Trigona (Ptilotrigona) lurida occidentalis; Moure, 1963: 263; Roubik, 1992: 502, 510, 523; Nates-Parra, 2001: 247.

Trigona (Tetragona) cf. heideri; Parra, 1984: 284.

Trigona (Tetragona) heideri; Parra, 1984: 288; 1990: 80, 83, 85, 86, 92, 95, 100, 102 (err. ident., oeste da Colômbia).

Ptilotrigona occidentalis; Coloma, 1986: 24, 132, 135.

Ptilotrigona lurida occidentalis; Roubik, 1989: 373; Camargo et al., 1992: 391; Galvis, 1987: 85-87.

Trigona (Ptilotrigona) lurida; Roubik, 1992: 503 (err. ident., Costa Rica); Nates-Parra, 2001: 240 (partim).

Trigona (Tetragona) lurida; Griswold et al., 1995: 684, 690 (err. ident., Costa Rica)

Diagnose. Operária. largura da cabeça entre ca. de 2,90$3,12 \mathrm{~mm}$; comprimento da asa anterior, desde o ápice do esclerito Costal, ca. de $9,5 \mathrm{~mm}$. Integumento predominantemente amarelo-castanho; mesoscuto amareladocastanho, exceto pelas faixas laterais e axilas amarelas; as pernas, às vezes bem enegrecidas, especialmente a perna III; clípeo usualmente por inteiro amarelo, sem manchas laterais perceptíveis (Fig. 30); membrana das asas anteriores suavemente tingida de amarelo-ferrugíneo, um pouco leitosa para o ápice; as microtríquias levemente mais escuras que a membrana, mais destacadas na metade basal da asa e apagadas para a metade apical. Macho. Cor do integumento como nas operárias; cerdas nos lados do esterno VI, delgadas, não distintas daquelas da área discal (Fig. 13); lados dos gonocoxitos abaulados (em P. lurida e P. pereneae, retos); parte distal dos ganchos da valva, ca. de 3,8 vezes mais longa que o bulbo basal; gonóstilos com o ápice dilatado em forma de cinzel (Fig. 19).

Machos. Figs. 13-15, 19.

Material-tipo. Síntipos, 3 operárias de "Nordwest-Ecuador, bei Cachavi [prov. San Javier de Cachabí], 500 Fuss [ca. $152 \mathrm{~m}$ de altitude], 
XI-XII, 1896, W.F.H. Rosemberg”, depositados no Zoologische Staatssammlung, München, Germany (ZSMC). Não examinados. Os dados sobre o holótipo de Trigona suffragata Cockerell, constam na lista abaixo.

Material examinado. COSTA RICA. Puntarenas: Corcovado Park, V.1982, K. Waddington (4 ops., RPSP); ibidem, Península de Osa, II.1985, D. Roubik (8 ops., 940639-646, RPSP); Esquinas, nr. Golfito, sem data, P. \& D. Allen (1 op., DZUP); Golfito, 26.VI.1976, M. Wasbauer, "malaise trap, 8AM 5PM" (2 ops., EMEC); ibidem, idem, 27.VI.1976 (2 ops., EMEC); ibidem, idem, United Fruit Co., 1.VI.1976, "along forest trail" (1 op., EMEC); ibidem, Golfito - United Fruit Co., 27.VI.1976, E. Ficher, M. Wasbauer (1 op., EMEC); ibidem, 12.VIII.1957, A. Menke (1 op., LACM); ibidem, idem, 21.VIII.1957 (1 op., LACM); ibidem, 23.VII.1957, Truxal, Menke (1 op., LACM); ibidem, idem, 24.VII.1957 (1 op., LACM); ibidem, idem, 27.VII.1957 (1 op., LACM); ibidem, idem, 29.VII.1957 (1 op., DZUP); Mogos, 7 Km N, Osa Peninsula, 19.VII.1992, D. W. Roubik, on baits (7 ops., 1 macho, STRI; 3 ops., RPSP); Rincón, 1.8 mi. W, Osa Peninsula, 9.II.1971, J. P. Donahue, C. L. Hogue (1 op., LACM); ibidem, 50 m, 25.V.1998, D. Roubik, baits (2 ops., STRI). PANAMÁ. Darién: Cana, 1000 m elev., I-6.II.2000, D. Roubik (5 ops., STRI; 2 ops., RPSP); COLÔMBIA. Chocó: Chocó, 1982, R. L. Dressler (1 op., STRI); La Concepción, 15 Km E. Quibdó, 12.V.1931, W.A. Archer, "feeding on badeafruit" (?), Hym. lot No. 7096, 236, "suffragata Ckll. Det. J. S. Moure" [2 ops.], "Ptilotrigona occidentalis (Schulz), Pe. J. S. Moure, 1984" [1 op.] (3 ops., DZUP); Nuquí, Estation Biolo. "El Amargal", 35 msnm, 28.XI.1999, L. Nuñez, R. Bemal (1 op., STRI). Valle del Cauca: Buenaventur [sic= Buenaventura], Bajo Colima $[s i c=$ Calima], 27.IX.1982, G. Parra, nest (2 ops., STRI; 3 ops., RPSP). Nariño: La Guayacana [= Guayacanes], 8.VIII.1956, Stuorn (?, ilegível) (1 op., DZUP). Departamento?: Colômbia: "Colombia SAmerica" [sem localidade especificada], etiq. manuscrita: "Letter Mar. 7-21, Harry Sargent"; etiq. vermelha: "Type no 24876 USNM"; etiq. manuscrita: "Trigona suffragata Ck1l. Type" (1 op., USNM). EQUADOR. Esmeraldas: Alto Tambo, 2.VIII.1991, D. Roubik, "rainy" (7 ops., STRI; 3 ops., RPSP); Esmeraldas, sem data, anônimo, AMNH, Dept. Invert. Zool. $\mathrm{n}^{\circ}$ 16048, “Trigona heideri var. occidentalis Schulz, Det. Schwarz” (1 op., RPSP).

Distribuição geográfica. Ocorre nas matas tropicais úmidas desde o noroeste do Equador até Darién no sul do Panamá e uma população, possivelmente isolada, na península de Osa, sudoeste da Costa Rica. Essa região de endemismo faunístico é comumente conhecida como província zoogeográfica Pacífico-Centroamericana ou componente biogeográfico Chocó-Centro-América (CAmargo \& Pedro 2003a). Além da localidade no sul de Darién (Fig. 46), não é conhecido qualquer outro registro de P. occidentalis no Panamá (RouBik 1992: 510), o que leva à suposição de que a população da península de Osa, realmente esteja isolada.

Nidificação - substrato e hábitat. De acordo com GALVIS (1987) e PARra (1990), P. occidentalis é conhecida na região do Chocó, Colômbia, como "abeja de brea" (abelhas de breu), e é explorada pelos nativos para a obtenção de mel e principalmente de breu. RoubiK (1989: 373), menciona que chega-se a obter ca. de $1 \mathrm{~kg}$ de resinas por ninho (armazenadas pelas abelhas em grandes depósitos no interior dos ninhos), que é utilizada para calafetação e impermeabilização de barcos pelos nativos. GALVIS (1987) analisou amostras de mel obtidas em ninhos das regiões entre os rios Calima, Dagua e Anchicaya, Costa do Pacífico, Província de Valle, Colômbia, e encontrou os seguintes parâmetros: $\mathrm{pH} 3,0$, baixa densidade, umidade acima de $21 \%$ e açúcares totais $(49,04 \%)$, com um alto teor de sacarose (37\%). Galvis não faz referência à quantidade de mel encontrado nos ninhos, e também não tem explicação para o alto conteúdo de sacarose. É possível que não se trate de mel (açúcares processados quimicamente pelas abelhas), mas apenas de substâncias adocicadas, como aquelas eventualmente armazenadas por $P$. lurida na região amazônica (ver dados bionômicos de P. lurida).

Outro aspecto que merece destaque é o fato de que tanto Galvis (1987) como PARRA (1990), que estudaram vários ninhos de P. occidentalis, não fazem qualquer referência à existência ou não de leveduras associadas ao pólen estocado, como observado em P. lurida por CAMARGO et al. (1992).

Os ninhos são construídos, usualmente, no interior de ocos espaçosos, com 20-30 cm de diâmetro, no tronco de grandes árvores vivas, a alturas variáveis, desde próximo ao solo até ca. de $15 \mathrm{~m}$ de altura. Às vezes, são encontrados em árvores mortas (PARRA 1990), ou em "associação" com termiteiros Nasutitermes (Isoptera, Termitidae), no interior de ocos (GALVIS 1987).

As observações sobre as estruturas do ninho, relatadas na literatura, não são muito detalhadas; de acordo com PARRA (1990), a entrada é constituída de um tubo cilíndrico, liso, de resinas endurecidas, sem ornamentação, com ca. de $5-20 \mathrm{~cm}$ de comprimento por 5-7 cm de diâmetro; os ninhos geralmente são grandes, com $100 \mathrm{~cm}$ ou mais de altura ou comprimento, por 20-30 cm de diâmetro, e delimitados por placas de batumes de cerume e própolis (com caracterísicas isotérmicas e impermeáveis à água, conforme GALVIS 1987). Os favos de cria, muito numerosos - entre 25 e 42 , são horizontais, superpostos, sustentados por conectivos de cerume e envolvidos por 3-4 lamelas de invólucro; as células medem $0,9 \mathrm{x} 0,5 \mathrm{~cm}$; os potes de mel e pólen, às vezes em conjuntos separados, medem $4 \times 2$ $3 \mathrm{~cm}$ (PARRA 1990). A julgar pelo número e tamanho dos favos, os ninhos são muito populosos, com ca. de 10.000-15.000 indivíduos ou mais.

É provável que nos ninhos de P. occidentalis, considerando as caracterísicas do batume acima descritas, muito semelhantes a de P. lurida (item "Estruturas internas"), também sejam encontradas leveduras em associação com o pólen.

Comportamento de defesa. As abelhas defendem o ninho com muita "agressividade", atacam em massa e se introduzem no cabelo, ouvidos, nariz, por baixo das roupas e mordem insistentemente; também depositam resinas (PARRA 1984: 83; GaLVIS 1987: 86).

Discussão. Os tipos de $P$. occidentalis não foram examinados, todavia a descrição de Schulz (1904) é precisa e, além disso, ele faz minuciosas comparações com $T$. heideri $\mathrm{e} T$. mocsaryi, de modo que não há dúvida quanto a sua identidade. Quanto a Trigona suffragata Cockerell, reexaminou-se o holótipo (n 24876 - USNM) e pôde-se confirmar seu status de sinônimo de $P$. occidentalis, conforme proposto por Moure 
(1963:263).

O reconhecimento desta espécie, em relação à $P$. lurida $\mathrm{e}$ $P$. pereneae, é bastante simples, conforme indicado na diagnose, principalmente pelo mesoscuto amarelado, ponta das asas de um amarelo leitoso, além dos caracteres dos machos (Figs. 13-15, 19). Um problema ainda mal solucionado, diz respeito à "população", provavelmente isolada, na península de Osa - Costa Rica. Embora os espécimens sejam indistinguíveis, em termos de morfologia e coloração, daqueles que ocorrem na região que vai do sul do Darién até o noroeste do Equador, há a possibilidade de que possam constituir uma espécie distinta. Há um grande espaço geográfico separando essas "duas" populações. Embora sejam bastante comuns em Osa, nunca foram coletadas (ao menos não se tem conhecimento), ao longo do Panamá, exceto no sul de Darién, próximo à fronteira com a Colômbia (RouBIK 1992: 510). Isso, considerando que as coletas de Meliponini no Panamá têm sido relativamente intensas, especialmente por D. W. Roubik. De qualquer forma, optou-se por uma decisão mais conservadora, até que mais evidências sejam acumuladas.

Agradecimentos. Aos pesquisadores e curadores dos museus (listados no item "Material e Métodos"), pelo empréstimo de material; Diretores e pesquisadores do Instituto Nacional de Pesquisas da Amazônia - INPA, Warwick E. Kerr, Enéas Salati, Roberto Vieira, José Alberto S. Nunes de Mello e Ozório J.M. Fonseca, que viabilizaram o apoio logístico, e também financeiro algumas vezes, para a realização de diversas das expedições ao Amazonas e que colocaram a nossa disposição os barcos e tripulação; aos Comandantes e tripulantes dos barcos "Marupiara", "Pyatã", "Capitão Walter" (fretado, particular), "Pium", "Uiara" e "Amanaí": Miguel Rodrigues de Souza, Demar Francisco Rodrigues, Antonio Torquato de Oliveira, José Fernandes Soares, Francisco Novaes de Andrade, João Batista de Sá Rodrigues, Limoel Pereira Gomes, Geraldo Seabra da Silva, Antonio Machado Gomes, Noronha Freitas de Souza, Marcos Antônio Freitas de Souza, Orlandino Alves da Silva, Raimundo Moreira de Carvalho, Cândido Garcia de Carvalho, Hermógenes Augusto da Silva, João de Jesus Costa, Lúcio da Silva Gomes, Vinícius Vasconcelos da Costa e Raimundo Laredo Smith. A Giovanni Onore, da Pontificia Universidad Catolica del Ecuador, Quito, pela doação de material; David W. Roubik, pelo empréstimo de material e informações sobre $P$. occidentalis; Claus Rasmussen, pela leitura e correções do manuscrito, pelo material, fotos e informações sobre as entradas dos ninhos de $P$. pereneae e P. lurida da região de Tarapoto, Peru; Pe. J. S. Moure, Márcio L. Oliveira, Elder Morato e Christopher Brown, pelos espécimens doados. A José Amílcar Tavares (técnico do Departamento Biologia, FFCLRP/USP), pela preparação, triagem dos espécimens e atualização dos fichários sobre Meliponini. Por último, um agradecimento especial a Menderson Mazucato (técnico aposentado do Departamento Biologia, FFCLRP/USP), pela participação em todas as viagens de coleta, preparação de material e companheirismo. A Albino M. Sakakibara pelas correções editorias e sugestões, e aos assessores anônimos pelos comentários e correções.

Esse trabalho se beneficiou do apoio financeiro das seguintes agências: INPA (projetos especiais, 1977 e 1979); FAPESP (procs. 79/ 1014, 85/2842-7, 92/2732-0 ZO e 98/11605-9); CNPq (proc. 406235/ 84ZO).

\section{REFERÊNCIAS}

Absy, M. L.; J. M. F. Camargo; W. E. Kerr \& I. P. A. Miranda. 1984. Espécies de plantas visitadas por Meliponinae (Hymenoptera:
Apoidea), para coleta de pólen na região do Médio Amazonas. Revista Brasileira de Biologia 44(2): 227-237.

AkahiRa, Y. \& D. Beig. 1967. Comparative study of corpora alata [sic] in Brazilian stingless bees. Papéis Avulsos de Zoologia 20(art. 160): $165-190$

Camargo, J. M. F. 1970. Ninhos e biologia de algumas espécies de Meliponídeos (Hymenoptera: Apidae) da região de Pôrto Velho, Território de Rondônia, Brasil. Revista de Biologia Tropical 16(2): 207-239.

CAmargo, J. M. F. 1988. Meliponinae (Hymenoptera, Apidae) da coleção do "Istituto di Entomologia Agraria", Portici, Itália. Revista Brasileira de Entomologia 32(3/4): 351-374.

Camargo, J. M. F. 1994. Biogeografia de Meliponini (Hymenoptera, Apidae, Apinae): A Fauna Amazônica, p. 46-59. In: R. Zucchi (coord.). Anais do $1^{\circ}$ Encontro sobre Abelhas. Ribeirão Preto, Universidade de São Paulo, Faculdade de Filosofia, Ciências e Letras de Ribeirão Preto, $x x+308$ p.

Camargo, J. M. F. 1996. Meliponini Neotropicais: O Gênero Camargoia Moure, 1989 (Apinae, Apidae, Hymenoptera). Arquivos de Zoologia 33(2): 71-92.

Camargo, J. M. F. \& J. S. Moure. 1988. Notas sobre os Meliponinae (Hymenoptera, Apidae) colecionados por Filippo Silvestri na bacia do Rio da Prata. Revista Brasileira de Entomologia 32(2): 293-314.

Camargo, J. M. F. \& J. S. Moure. 1996. Meliponini Neotropicais: o gênero Geotrigona Moure, 1943 (Apinae, Apidae, Hymenoptera), com especial referência à filogenia e biogeografia. Arquivos de Zoologia 33(3): 95-161.

Camargo, J. M. F. \& S. R. M. Pedro. 2003a. Meliponini Neotropicais: o gênero Partamona Schwarz, 1939 (Hymenoptera, Apidae, Apinae) - bionomia e biogeografia. Revista Brasileira de Entomologia 47(3): 311-372.

Camargo, J. M. F. \& S. R. M. Pedro. 2003b. Sobre as relações filogenéticas de Trichotrigona Camargo \& Moure (Hymenoptera, Apidae, Meliponini), p. 109-122. In: G. A. R. Melo \& I. Alves-Dos-Santos (eds.). Apoidea Neotropica: Homenagem aos 90 Anos de Jesus Santiago Moure. Criciúma, Editora UNESC, xvi+320 p.

Camargo, J. M. F.; M. V. B. Garcia; E. R. Q. Júnior \& A. Castrillon. 1992. Notas prévias sobre a bionomia de Ptilotrigona lurida (Hymenoptera, Apidae, Meliponinae): associação de leveduras em pólen estocado. Boletim do Museu Paraense Emílio Goeldi, Série Zoologia, 8(2): 391-395.

Cockerell, T. D. A. 1912. New bees from Brazil. Psyche 19: 41-61.

Cockerell, T. D. A. 1920. Some Neotropical meliponid bees. Bulletin of the American Museum of Natural History 42: 459-468.

Cockerell, T. D. A. 1922. Bees in the collection of the United States National Museum - 4. Proceedings of the United States National Museum 60(18): 1-20.

Cockerell, T. D. A. 1930. Descriptions and records of bees. - CXXII. Annals and Magazine of Natural History, ser. 10, 5: 156-163.

Cockerell, T. D. A. 1934. Some African meliponine bees. Revue de Zoologie et de Botanique Africaines 26: 46-62.

Coloma, L. A. R. 1986. Contribución para el conocimiento de las abejas sin aguijón (Meliponinae, Apidae, Hymenoptera) de Ecuador. Monografia de Licenciatura. Quito, Pontificia Universidad Catolica del Ecuador, 146 p.

Cruz-landim, C. \& M. H. V. B. Mota. 1990. Occurrence of tegumentary glands in stingless bees (Hymenoptera, Apidae, Meliponinae), p. 587-588. In: G. K. Veeresh; B. Mallik \& C. A. Viraktamath (eds.). Social Insects and the Environment, Proceedings of the 11th International Congress of IUSSI, Bangalore, India. New Delhi, Mohan Primlani for Oxford \& IBH Publishing Co., xxxi+765 p.

Cunha, R. A. 1973. Taxonomia numérica de alguns Meliponinae (Hymenoptera - Apidae). Ciência Biológica (Portugal) 1: 2542 (separata p. 1-18).

Cunha, R. A. 1991. Revisão da taxonomia de alguns Meliponinae por métodos fenéticos (Hym., Apidae). Naturalia 16: 33-53.

Dalla Torre, K. W. (C. G.). 1896. Catalogous Hymenopterorum; Hucusque Descriptorum Systematicus et Synonymicus. Vol. 10 Apidae (Anthophila). Leipzig, Engelmann, viii+643 p. 
DucKE, A. 1902a. Beobachtungen über Blütenbesuch, Erscheinungszeit etc. der bei Pará vorkommenden Bienen. Allgemeine Zeitschrift für Entomologie 17: 321-326.

Ducke, A. 1902b. Die stachellosen Bienen (Melipona Ill.) von Pará, nach dem Meteriale der Sammlung des Museu Goeldi beschrieben. Zoologische Jahrbücher Abteilung für Systematik, Geographie und Biologie der Tiere 17: 285-328.

Ducke, A. 1907. Contribution a la Connaissance de la Faune Hyménoptérologique du Nort-Est du Brésil. Revue d'Entomologie 17: 73-96.

DuCKe, A. 1916a. Enumeração dos Hymenopteros colligidos pela Commissão. Commissão de Linhas Telegraphicas e Estrategicas de Matto Grosso ao Amazonas, publicação no. 35, annexo 5, Hist. Nat. Zool., Rio de Janeiro, Ministério da Agricultura, p. 3-16.

Ducke, A. 1916b. Revisão das espécies de abelhas do Brasil. Commissão de Linhas Telegraphicas e Estrategicas de Matto Grosso ao Amazonas, publicação no. 35, annexo 5, Hist. Nat. Zool., Rio de Janeiro, Ministério da Agricultura, p. 17-177 +Figs. 13-25 + errata.

Ducke, A. 1925. Die stachellosen Bienen (Melipona) Brasiliens. Nach morphologischen und ethologischen Merkmalen geordnet. Zoologische Jahrbücher Abteilung für Systematik, Geographie und Biologie der Tiere 49: 335-448+Figs. 1-24, pls. 3,4 .

ENGEL, M. S. 2001. A monograph of the Baltic amber bees and evolution of the Apoidea (Hymenoptera). Bulletin of the American Museum of Natural History 259: $192 \mathrm{p}$.

Engel, M. S. \& F. Dingemans-Bakels. 1980. Nectar and pollen resources for stingless bees (Meliponinae, Hymenoptera) in Surinam (South America). Apidologie 11(4): 341-350.

Falcão, M. A.; R. M. S. Galvão; C. R. Clement; S. A. N. Ferreira \& S. G. Sampaio. 2000. Fenologia e produtividade do araçá-boi (Eugenia stipitata, Myrtaceae) na Amazônia Central. Acta Amazonica 30(1): 9-21.

Friese, H. 1900. Neue Arten der Bienengattungen Melipona Ill. und Trigona Jur. Természetrajzi Füzetek 23: 381-391.

Friese, H. 1903. Neue Meliponiden II. (Hym.). Zeitschrift für Systematische Hymenopterologie und Dipterologie 3: 359361

Galvis, C. E. H. 1987. Biologia de la abeja de brea Ptilotrigona lurida o. y composicion de sus productos. Cespedesia 14-15(53-56): 8587

Griswold, T.; F. D. Parker \& P. E. Hanson. 1995. The Bees (Apidae), p. 650-691. In: P. E. Hanson \& I. D. Gauld (eds.). The Hymenoptera of Costa Rica. Oxford, Oxford University Press, 893 p.

Heard, T. A. 1999. The role of stingless bees in crop pollination. Annual Review of Entomology 44: 183-206.

InERING, H. von. 1930. Biologia das abelhas melliferas do Brasil. Boletim de Agricultura, Secretaria do Estado de São Paulo, 31: 435-506, 649-714, Figs. 1-22, pl.1 (tradução de H. von Ihering, 1903, por R. von Ihering e B. Sampaio de Corrêa).

Ihering, R. von. 1968. Dicionário de Animais do Brasil. Brasília, Editora da Universidade de Brasília, 790 p.

Kerr, W. E.; S. F. Sakagami; R. Zucchi; V. Portugal-araújo \& J. M. F. CAmargo. 1967. Observações sobre a arquitetura dos ninhos e comportamento de algumas espécies de abelhas sem ferrão das vizinhanças de Manaus, Amazonas (Hymenoptera, Apoidea), p. 255-309. In: H. Lent (ed.). Atas do Simpósio sobre a Biota Amazônica, vol. 5 (zool.). Rio de Janeiro, Conselho Nacional de Pesquisas, 603 p.

Lenko, K. \& N. Papavero. 1996. Insetos no Folclore. 2a. ed. rev. ampl. São Paulo, Plêiade, FAPESP, 468 p.

LoKvam, J. \& J. F. BRADDOCK. 1999. Anti-bacterial function in the sexually dimorphic pollinator rewards of Clusia grandiflora (Clusiaceae). Oecologia 119: 534-540.

Lopes, A. V. \& I. C. MAchado. 1998. Floral biology and reproductive ecology of Clusia nemorosa (Clusiaceae) in northeastern Brazil. Plant Systematic and Evolution 213: 71-90.

LuTz, F. E. 1924. Apparently non-selective characters and combinations of characters, including a study of ultraviolet in relation to the flower visiting habits of insects. Annals of the New York Academy of Sciences 29: 181-283.

Maddison, W. P. \& D. R. Maddison. 1992. MacClade: Analysis of phylogeny and character evolution. Version 3 (programa, versão 3.05). Sunderland, Sinauer Associates, Inc. Publishers.

Marianno, J. 1911. Ensaio sobre as Meliponidas do Brasil. Rio de Janeiro, edição do Autor, $140 \mathrm{p}$.

Mesquita, R. C. G. \& C. H. Franciscon. 1995. Flower visitors of Clusia nemorosa G. F. W. Meyer (Clusiaceae) in an Amazonian whitesand campina. Biotropica 27(2): 254-257.

Michener, C. D. 1990. Classification of the Apidae (Hymenoptera). The University of Kansas Science Bulletin 54(4): 75-164.

Michener, C. D. 2000. The Bees of the World. Baltimore, The Johns Hopkins University Press, xiv $+913 p ., 16$ pranchas.

Michener, C. D. \& D. W. RoubiK. 1993. Observations on the labium of meliponine bees (Hymenoptera: Apidae), p. 251-265. In: T. Inouk \& S. Yamane (eds.). Evolution of Insect Societies: Comparative Sociology of Bees, Wasps and Ants. Tokyo, Hakuhin-sha Publishing Co., $532 \mathrm{p}$.

Mota, M. H. V. B. 1992. Estudo comparativo das glândulas epidérmicas do abdômen dos Meliponíneos (Hymenoptera, Apidae, Meliponinae), p. 320-322. In: A. E. E. SoARES \& D. DE Jong (eds.) Pesquisas com abelhas no Brasil. Ribeirão Preto, Sociedade Brasileira de Genética, $680 \mathrm{p}$.

Moure, J. S. 1944. Abejas del Perú. Boletin del Museo de Historia Natural "Javier Prado" 8(28,29): 67-75.

Moure, J. S. 1951. Notas sôbre Meliponinae (Hymenopt. - Apoidea). Dusenia 2(1): 25-70

Moure, J. S. 1963. Sôbre a identidade dos Meliponinos descritos por Spinola em 1853 (Hymenoptera, Apoidea). Anais da Academia Brasileira de Ciências 35(2): 257-269.

Moure, J. S. 1989. Camargoia, um novo gênero neotropical de Meliponinae (Hymenoptera: Apoidea). Boletim do Museu Paraense Emílio Goeldi, Série Zoologia, 5(1): 71-78.

NAtes-PARRA, G. 1983. Abejas de Colombia: I. Lista preliminar de algunas especies de abejas sin aguijón (Hymenoptera, Apidae, Meliponinae) Revista de Biologia Tropical 31(1): 155-158.

Nates-ParRa, G. 2001. Las abejas sin aguijón (Hymenoptera: Apidae: Meliponini) de Colombia. Biota Colombiana 2(3): 233-248.

Nogueira-neto, P. 1970. A Criação de Abelhas Indígenas sem Ferrão. São Paulo, Tecnapis, Chácaras e Quintais, 365 p.

Nogueira-neto, P. 1997. Vida e Criação de Abelhas Indígenas Sem Ferrão. São Paulo, Nogueirapis, 446 p.

Oliveira, M. L. 2001. Stingless bees (Meliponini) and orchid bees (Euglossini) in terra firme tropical forests and forest fragments, $\mathrm{p}$. 208-218. In: R. O. Bierregaard JR., C. Gascon, T. E. Lovejoy \& R. C. G. Mesquita (eds.). Lessons from Amazonia. The Ecology and Conservation of a Fragmented Forest. New Haven, Yale University Press, $544 \mathrm{p}$.

Oliveira, M. L. 2002. As abelhas sem ferrão na vida dos seringueiros e dos Kaxinawá do alto rio Juruá, Acre, Brasil, p. 615-630. In: M. C. Cunha \& M. B. Almeida (orgs.). Enciclopédia da Floresta. O Alto Juruá: Práticas e Conhecimentos das Populações. São Paulo, Companhia das Letras, 735 p.

Oliveira, M. L. \& E. F. Morato. 1994. Abelhas sem ferrão (Apidae, Meliponinae) do estado do Acre, p. 291. In: R. Zucchi (coord.) Anais do $1^{\circ}$ Encontro sobre Abelhas. Ribeirão Preto, Universidade de São Paulo, Faculdade de Filosofia, Ciências e Letras de Ribeirão Preto, $x x+308$ p.

Oliveira, M. L.; E. F. Morato \& M. V. B. Garcia. 1995. Diversidade de espécies e densidade de ninhos de abelhas sociais sem ferrão (Hymenoptera, Apidae, Meliponinae) em floresta de terra firme na Amazônia Central. Revista Brasileira de Zoologia 12(1): $13-24$.

Parra, G. V. 1984. Censo parcial de las abejas sin aguijón (Apidae Meliponinae) del Occidente Colombiano. Cespedesia 13(49-50): 277-290.

Parra, G. V. 1990. Bionomia de las abejas sin aguijon (Apidae Meliponinae) del occidente colombiano. Cespedesia 57-58: 77 116. 
Pedro, S. R. M. \& J. M. F. Camargo. 2003. Meliponini neotropicais: o gênero Partamona Schwarz, 1939 (Hymenoptera, Apidae). Revista Brasileira de Entomologia 47(Supl. 1): 1-117.

Posey, D. A. 1983. Keeping of stingless bees by the Kayapó indians of Brasil. Journal of Ethnobiology 3(1): 63-73.

Ramalho, M.; A. Kleinert-Giovannini \& V. L. Imperatriz-Fonseca. 1990 Important bee plants for stingless bees (Melipona and Trigonini) and Africanized honeybees (Apis mellifera) in Neotropical habitats: a review. Apidologie 21: 469-488.

RÊGo, M. \& C. Brito. 1996. Abelhas sociais (Apidae: Meliponini) em um ecossistema de cerrado s.l. (Chapadinha - MA, BR): distribuição dos ninhos, p. 238-247. In: C. A. Garófalo (org.). Anais do II Encontro Sobre Abelhas. Ribeirão Preto, Universidade de São Paulo, Faculdade de Filosofia, Ciências e Letras de Ribeirão Preto, $\mathrm{xxii}+351 \mathrm{p}$.

Reyne, A. 1962. Angelloze bijen (Meliponidae) voorkomende in Suriname. Entomologische Berichten 22(2): 30-37.

RoubiK, D. W. 1989. Ecology and Natural History of Tropical Bees. New York, Cambridge University Press, $\mathrm{x}+514 \mathrm{p}$.

Roubik, D. W. 1992. Stingless bees: a guide to Panamanian and Mesoamerican species and their nests (Hymenoptera: Apidae: Meliponinae), p. 495-524. In: D. Quintero \& A. Aiello (eds.). Insects of Panama and Mesoamerica. Selected Studies, Oxford, Oxford University Press, 692 p.

Schulz, W. A. 1904 (1903). Hymenopteren Amazoniens. Sitzungsberichte der Königlich Bayerischen Akademie der Wissenschaften, Mathematisch-physikalische Klasse 33: 815-832.

Schwarz, H. F. 1932. The genus Melipona: the type genus of the Meliponidae or stingless bees. Bulletin of the American Museum of Natural History 63: 231-460+pls. 1-10.

Schwarz, H. F. 1937. Results of the Oxford University Sarawak (Borneo) expeditions: Bornean stingless bees of the genus Trigona. Bulletin of the American Museum of Natural History 73: 281-329.

Schwarz, H. F. 1938. The stingless bees (Meliponidae) of British Guiana and some related forms. Bulletin of the American Museum of
Natural History 74: 437-508 +10 pls.

Schwarz, H. F. 1940. Additional species and records of stingless bees (Meliponidae) from British Guiana. American Museum Novitates 1078: $1-12$.

Schwarz, H. F. 1943. New Trigona bees from Peru. American Museum Novitates 1243: 1-10.

Schwarz, H. F. 1948. Stingless bees (Meliponidae) of the Western Hemisphere. Bulletin of the American Museum of Natural History 90: xvii +1-546.

Silveira, F. A.; G. A. R. Melo \& E. A. B. Almeida. 2002. Abelhas Brasileiras. Sistemática e Identificação. Belo Horizonte, F. A. Silveira, $253 \mathrm{p}$.

Smith, F. 1854. Catalogue of Hymenopterous Insects in the Collection of the British Museum. Part 2. London, British Museum, p. 199-465+pls.vii-xii.

Spinola, M. 1853. Compte rendu des hyménoptères inédits provenants du voyage entomologique de M. Ghiliani dans le Para en 1846. Memorie della Reale Accademia delle Scienze di Torino, série 2, 13: 19-94.

Swofford, D. L. 2002. PAUP*. Phylogenetic Analysis Using Parsimony (*and Other Methods), version 4. Sunderland, Sinauer Associates.

Waddington, K. D.; L. H. Herbst, \& D. W. Roubik. 1986. Relationship between recruitment systems of stingless bees and within-nest worker size variation. Journal of the Kansas Entomological Society 59(1): 95-102.

Wille, A. 1979. Phylogeny and relationships among the genera and subgenera of the stingless bees (Meliponinae) of the world. Revista de Biologia Tropical 27(2): 241-277.

Wille, A. \& C. D. Michener. 1973. The nest architecture of stingless bees with special reference to those of Costa Rica (Hymenoptera, Apidae). Revista de Biologia Tropical 21(sup1.1): 1-128.

Zanella, F. C. V.; M. L. Oliveira \& M. C. Gaglianone. 2000. Standardizing lists of locality data for examined specimens in systematics and biogeography studies of New World taxa. Biogeographica 76(4): 145-160. 